ЭПИДЕМИОЛОГИЧЕСКИЕ ХАРАКТЕРИСТИКИ САХАРНОГО ДИАБЕТА

В РОССИЙСКОЙ ФЕДЕРАЦИИ: КЛИНИКО-СТАТИСТИЧЕСКИЙ АНАЛИЗ ПО ДАННЫМ ФЕДЕРАЛЬНОГО РЕГИСТРА САХАРНОГО ДИАБЕТА НА 01.01.2021

(с) И.И. Дедов, М.В. Шестакова, О.К. Викулова*, А.В. Железнякова, М.А. Исаков

Национальный медицинский исследовательский центр эндокринологии, Москва

ОБОСНОВАНИЕ. Одним из приоритетных направлений развития системы здравоохранения является снижение медико-социального ущерба, обусловленного ростом распространенности сахарного диабета (СД), что обосновывает актуальность развития регистра СД в качестве основной информационно-аналитической платформы клинико-эпидемиологического мониторинга СД в Российской Федерации (РФ).

ЦЕЛЬ. Провести динамический (2016-2020 гг.) анализ эпидемиологических характеристик СД в РФ (распространенности, заболеваемости, смертности), распространенности осложнений, состояния углеводного обмена (по уровню гликированного гемоглобина $\left.\left(\mathrm{Hb}_{1 c}\right)\right)$ и динамики структуры сахароснижающей терапии (ССТ) по данным Федерального регистра СД (ФРСД).

МАТЕРИАЛЫ И МЕТОДЫ. Объект исследования: база данных регистра СД (http://diaregistry.ru), включающая 84 региона РФ. Данные представлены в динамике 2016-2020 гг.

РЕЗУЛЬТАТЫ. Общая численность пациентов с СД в РФ, состоящих на диспансерном учете, на 01.01 .2021 г., по данным регистра, составила 4799552 (3,23\% населения РФ), из них: СД1 - 5,5\% (265,4 тыс.), СД2 - 92,5\% (4,43 млн), другие типы СД - 2,0\% (99,3 тыс.). Динамика распространенности составила при СД1 168,7 $\rightarrow 180,9 / 100$ тыс. населения, при СД2 $2709 \rightarrow 3022 / 100$ тыс. населения; заболеваемости - при СД1 10,5 $\rightarrow 7,7 / 100$ тыс. населения, при СД2 219,6 $\rightarrow 154,2 / 100$ тыс. населения. Половозрастные характеристики: доля мужчин при СД1 54\%, при СД2 30\%; наибольшая доля пациентов с СД1 в возрасте 30-39 лет, с СД2 - 65-69 лет. Смертность: СД1 3,0 $\rightarrow 2,7 / 100$ тыс. населения, СД2 87,7 $\rightarrow 93,9 / 100$. тыс. населения, основная доля приходится на сердечно-сосудистые причины: при СД1 38,1\%, при СД2 52,0\%. Средний во3раст смерти при СД1 составил 53,2 года, в динамике у мужчин 50,7 $\rightarrow$ 50,5 года, у женщин 58,7 $\rightarrow 55,2$ года; при СД2 73,5 года, у мужчин 70,2 $\rightarrow 70,1$ лет, у женщин 75,7 $\rightarrow 75,4$ года. Средняя длительность СД до момента смерти пациентов: при СД1 17,4 $\rightarrow 19,0$ года; при СД2 11 $\rightarrow 11,4$ года. Частота диабетических осложнений при СД1 и СД2: нейропатии 43,3\% и 24,4\%, нефропатии 25,9\% и 18,4\%, ретинопатии 31,7\% и 13,5\% соответственно. Доля пациентов с НbА $<$ < $7 \%$ : при СД1 $32,3 \% \rightarrow 36,9 \%$, при СД2 51,9\% $\rightarrow 52,1 \%$, c HbA $_{1 с} \geq 9,0 \%:$ при СД1 23,1\% $\rightarrow 18,7 \%$, при СД2 8,9\% $\rightarrow 8,0 \%$. Структура терапии при СД2: пероральные сахароснижающие препараты (ССП) - 76,2\% пациентов (монотерапия - 44,1\%; комбинация 2-х ССП - 28,9\%, 3-х препаратов - 3,2\%), инсулинотерапия - 18,8\%, без медикаментозной терапии - 4,9\%.

ЗАКЛЮчЕНИЕ. Выполненный анализ демонстрирует важность динамической оценки эпидемиологических характеристик и мониторинга клинических данных о пациентах с СД посредством регистра для оценки качества оказания диабетологической помощи и перспектив ее развития.

КЛЮЧЕВЫЕ СЛОВА: сахарный диабет (СД); регистр сахарного диабета (ФРСД); распространенность; заболеваемость; смертность; сахароснижающая терапия

\title{
EPIDEMIOLOGICAL CHARACTERISTICS OF DIABETES MELLITUS IN THE RUSSIAN FEDERATION: CLINICAL AND STATISTICAL ANALYSIS ACCORDING TO THE FEDERAL DIABETES REGISTER DATA OF 01.01.2021
}

(c) Ivan I. Dedov, Marina V. Shestakova, Olga K. Vikulova*, Anna V. Zheleznyakova, Mikhail A. Isakov

Endocrinology Research Centre, Moscow, Russia

BACKGROUND. One of the priority directions in the development of the health care system is to reduce the medical and social damage caused by the increase in the prevalence of diabetes mellitus (DM). From this point of view, the development of a diabetes register is very important as the main information and analytical platform for clinical and epidemiological monitoring of diabetes in the Russian Federation (RF).

AIMS. The aim of our study was to analyze a dynamic (2016-2020) of the epidemiological characteristics of diabetes mellitus in the Russian Federation (prevalence, morbidity, mortality), the prevalence of complications, the level of $\mathrm{HbA}_{1 \mathrm{c}}$ and the dynamics of the structure of glucose-lowering therapy (GLT) according to the Federal Diabetes Register (FDR). 
MATERIALS AND METHODs. The database of FRD (http://diaregistry.ru) 84 regions of the RF. The data are presented in dynamics $2016 \rightarrow 2020$.

RESULTS. The total number of DM patients in the RF as of 01.01 .2021 was $4,799,552$ (3.23\% of the population), including: Type 1 (T1) - 5.5\% (265.4 ths) , T2 - 92.5\% (4.43 million), other DM types - 2.0\% (99.3 ths). The dynamics of prevalence was $168.7 \rightarrow 180.9 / 100$ ths people with $\mathrm{T} 1$, and $2709 \rightarrow 3022 / 100$ ths people with T2; morbidity in $\mathrm{T} 110.5 \rightarrow 7.7 / 100$ ths population, in T2 $219.6 \rightarrow 154.2 / 100$ ths population. Age and sex characteristics: the proportion of men in T1 $-54 \%$, in $\mathrm{T} 2-30 \%$; the max proportion of patients with T1 at the age of 30-39 years, T2 65-69 years. Mortality: T1 3.0 $\rightarrow 2.7 / 100$ ths population, T2 $87.7 \rightarrow 93.9 / 100$ ths of the population, the main cause of death was cardiovascular: in T1 38,1\% cases, in T2 $52,0 \%$. Life expectancy (average age of death of patients): T1 was 53.2years, the dynamics in males $50.7 \rightarrow 50.5 y e a r s$, females $58.7 \rightarrow 55.2$ years; in T2 -73.5 years, males $70.2 \rightarrow 70.1$ years, females $75.7 \rightarrow 75.4$ years. The dynamic of DM duration until the death: in T1 17.4 $\rightarrow 19.0$ years; in T2 $11 \rightarrow 11.4$ years. The incidence of diabetic complications in $\mathrm{T} 1$ and $\mathrm{T} 2$ patients: neuropathy $43.3 \%$ and $24.4 \%$, nephropathy (CKD) $25.9 \%$ and $18.4 \%$, retinopathy $31.7 \%$ and $13.5 \%$, respectively. The proportion of patients with $\mathrm{HbA}_{1 \mathrm{c}}<7 \%$ : in $1132.3 \% \rightarrow 36.9 \%$, in T2 $51.9 \% \rightarrow 52.1 \%$, with $\mathrm{HbA} 1 \mathrm{c} \geq 9.0 \%$ in $123.1 \% \rightarrow 18.7 \%$, in $228.9 \% \rightarrow 8.0 \%$. The structure GLT in T2 patients: glucose lowering medications (GLM) - 76.2\% (monotherapy - 44.1\%; combination of $2 \mathrm{GLM}-28.9 \%, 3 \mathrm{GLM}-3.2 \%$ ), insulin therapy in $18,8 \%$, without drug therapy in $4.9 \%$.

CONCLUSIONS. The performed analysis demonstrates the importance of dynamic assessment of epidemiological characteristics and monitoring of clinical data on patients with diabetes through a registry for assessing the quality of diabetes care and the prospects for its development.

KEYWORDS: diabetes mellitus (DM); the register of diabetes mellitus (FDR); diabetes prevalence; mortality in DM; cause of death; hypoglycemic therapy

Сахарный диабет (СД) относится к категории социально значимых неинфекционных заболеваний с эпидемическими темпами роста распространенности. По последним данным Международной федерации диабета (International Diabetes Federation, IDF), количество пациентов с СД в мире достигло 463 млн, что опередило ранее прогнозируемые темпы прироста на 10-12 лет, а к 2045 г. ожидается увеличение на 51\%, до 700 млн человек [1]. В Российской Федерации (РФ), как и во многих странах мира, продолжается рост распространенности СД - с 2000 г. численность пациентов с СД увеличилась более чем в 2 раза [2].

В РФ в 1996 г. в рамках Федеральной целевой программы «Сахарный диабет» был организован общенациональный Федеральный регистр пациентов с СД (ФРСД) [3]. С 2014 г. ФРСД был переведен в онлайн-формат ввода данных, что позволило осуществлять клинико-эпидемиологический мониторинг ключевых показателей заболевания в режиме реального времени в масштабах всей страны. За прошедшие 25 лет работа регистра сыграла ключевую роль в оценке распространенности СД и диабетических осложнений. Потенциал практического применения регистра связан с его использованием не только в качестве статистической системы эпидемиологических характеристик СД, но именно ключевых клинико-практических аспектов: анализа сахароснижающей терапии (ССТ), ее соответствия клиническим рекомендациям, внедрения инновационных препаратов и других клинических и организационных показателей диабетологической службы.

Опыт работы в течение 2020 г. в условиях пандемии новой коронавирусной инфекции (COVID-19) показал преимущества регистра как системы непрерывного мониторинга с СД в режиме реального времени в плане наиболее эффективной стратегии ведения пациентов для снижения риска неблагоприятных исходов [4].

Задачи регистра СД в рамках основных направлений деятельности НМИЦ включают:
- оценку распространенности СД и диабетических осложнений в России в целом и в субъектах РФ;

- анализ заболеваемости СД;

- анализ уровня и причин смертности пациентов с СД;

- оценку потребности в лекарственных препаратах и средствах самоконтроля;

- анализ соответствия ССТ в реальной клинической практике существующим клиническим рекомендациям и стандартам оказания медицинской помощи;

- анализ эффективности внедрения и доступности новых диагностических и лечебных методов.

Регистр позволяет увидеть фактическое состояние диабетологической помощи (уровень $\mathrm{HbA}_{1 c^{\prime}}$ частоту осложнений, структуру терапии, структуру смертности); оценить соответствие реальной клинической помощи стандартам ведения пациентов с СД; провести анализ причин, препятствующих достижению целевых показателей контроля СД; провести выбор приоритетных направлений развития диабетологической службы в масштабах отдельного лечебно-профилактического учреждения (ЛПУ), региона, РФ; осуществлять контроль за льготным лекарственным обеспечением на региональном и федеральном уровне.

\section{ЦЕЛЬ}

Провести динамический анализ эпидемиологических характеристик СД в РФ (распространенности, заболеваемости, смертности), распространенности осложнений, состояния углеводного обмена (по уровню гликированного гемоглобина $\left.\left(\mathrm{HbA}_{1 c}\right)\right)$ и динамики структуры ССТ по данным ФРСД.

\section{МЕТОДЫ}

Объектом исследования являлась база данных ФРСД, включающая 84 региона РФ, на 01.01.2021 г. 
При расчете показателей распространенности и заболеваемости СД использовались данные численности населения субъектов РФ Федеральной службы государственной статистики (Росстат) [5]. По данным Росстат также указана численность пациентов с СД в Чукотском автономном округе, не включенном в регистр.

Показатели распространенности и заболеваемости СД 1 и 2 типа (СД1 и СД2) представлены в динамике за период 2016-2020 гг.

Анализ половозрастных характеристик представлен за 2020 г;; в него включались пациенты с наличием всех необходимых параметров (пол, возраст, тип СД) и исключались пациенты с ошибочными демографическими характеристиками.

Динамика причин смерти, контроля углеводного обмена и структуры ССТ представлена по данным ФРСД (84 региона) за 2020 г. и в динамике 2016-2020 гг. Из динамического анализа ССТ исключались пациенты, у которых не заполнен раздел терапии.

\section{Терминология}

Распространенность - показатель, оценивающий количество всех случаев заболевания, зарегистрированных в текущем календарном году, рассчитывается на 100 тыс. населения соответствующей возрастной группы.

Заболеваемость (первичная, по обращаемости) показатель, оценивающий количество новых случаев заболевания, впервые зарегистрированных в текущем календарном году, рассчитывается на 100 тыс. населения соответствующей возрастной группы.

Смертность - показатель, оценивающий количество смертей у лиц с данным заболеванием, рассчитывается на 100 тыс. населения соответствующей возрастной группы.

Дети - лица в возрасте до 15 лет (0-<15).

Подростки - лица в возрасте от 15 лет до 18 лет $(15-<18)$.

Взрослые - лица старше 18 лет.

\section{Этическая экспертиза}

Протокол исследования №20 от 14 декабря 2016 г. был рассмотрен локальным этическим комитетом ФГБУ «НМИЦ эндокринологии» Минздрава России, принято положительное решение.

\section{РЕЗУЛЬТАТЫ}

Анализ распространенности сахарного диабета

в Российской Федерации

На 01.01.2021 г. в онлайн-регистр СД включено 84 региона РФ, 4658 ЛПУ. Общая численность пациентов с СД в РФ, состоящих на диспансерном учете, на 01.01.2021 г., по данным регистра, составила 4799552 (3,23\% населения РФ), из них: СД1 - 5,5\% (265,4 тыс.), СД2 - 92,5\% (4,43 млн), другие типы СД - 2,0\% (99,3 тыс.) (рис. 1). Группа «другие типы СД» включала пациентов с нарушением толерантности к глюкозе (НТГ) - 67,3 тыс., нарушением гликемии натощак (НГН) - 12,1 тыс., гестационным СД (9,4 тыс.) и другими типами СД (10,4 тыс.).

Показатели распространенности СД1 и СД2 в РФ по данным каждого региона на 01.01.2021 г. представлены на рис. 2 и 3. Показатели распространенности СД в каждом из 85 регионов в различных возрастных группах (Чукотсткий АО по данным Росстат) представлены в приложении 1, табл. 1-4: все возрастные группы, дети, подростки и взрослые соответственно.

Распространенность СД1 в 2020 г. в среднем в РФ составила 180,9/100 тыс. населения (рис. 2), наблюдались различия между регионами с присутствием «географического градиента»: бо́льшей распространенностью СД1 в северо-западных регионах нашей страны.

Распространенность СД2 в 2020 г. в среднем в РФ составила 3022,1/100 тыс. населения (рис. 3). Выраженную вариабельность между регионами при СД2 сложно трактовать этническими и генетическими различиями. Учитывая общепопуляционные факторы развития СД2, на показатель распространенности могут влиять организационные факторы, такие как различия в скрининге СД и эффективности его выявления в группах риска.

Показатели распространенности СД1 и СД2 в динамике за период 2016-2020 гг. представлены на рис. 4 - отмечается увеличение распространенности обоих типов СД, преимущественно за счет СД2.

\section{Анализ заболеваемости сахарным диабетом}

в Российской Федерации

Динамика заболеваемости СД в 2016-2020 гг. составила при СД1 10,5-7,7/100 тыс. населения, при СД2 - 219,6154,2/100 тыс. населения, абсолютные значения представлены на рис. 5. С 2016 г. отмечался прирост более 300 тыс.

\begin{tabular}{lc|c}
\hline & СД 1 & СД 2 \\
\hline Дети, $\mathbf{n}$ & 31407 & 673 \\
\hline Подростки, $\mathrm{n}$ & 11544 & 250 \\
\hline Взрослые, $\mathbf{n}$ & 222449 & 4433953 \\
\hline Всего, $\mathbf{n}$ & $\mathbf{2 6 5 4 0 0}$ & $\mathbf{4 4 3 4 8 7 6}$ \\
\hline
\end{tabular}

Другие типы СД, n

Всего на 01.01.2021 r.
99276

4799552 


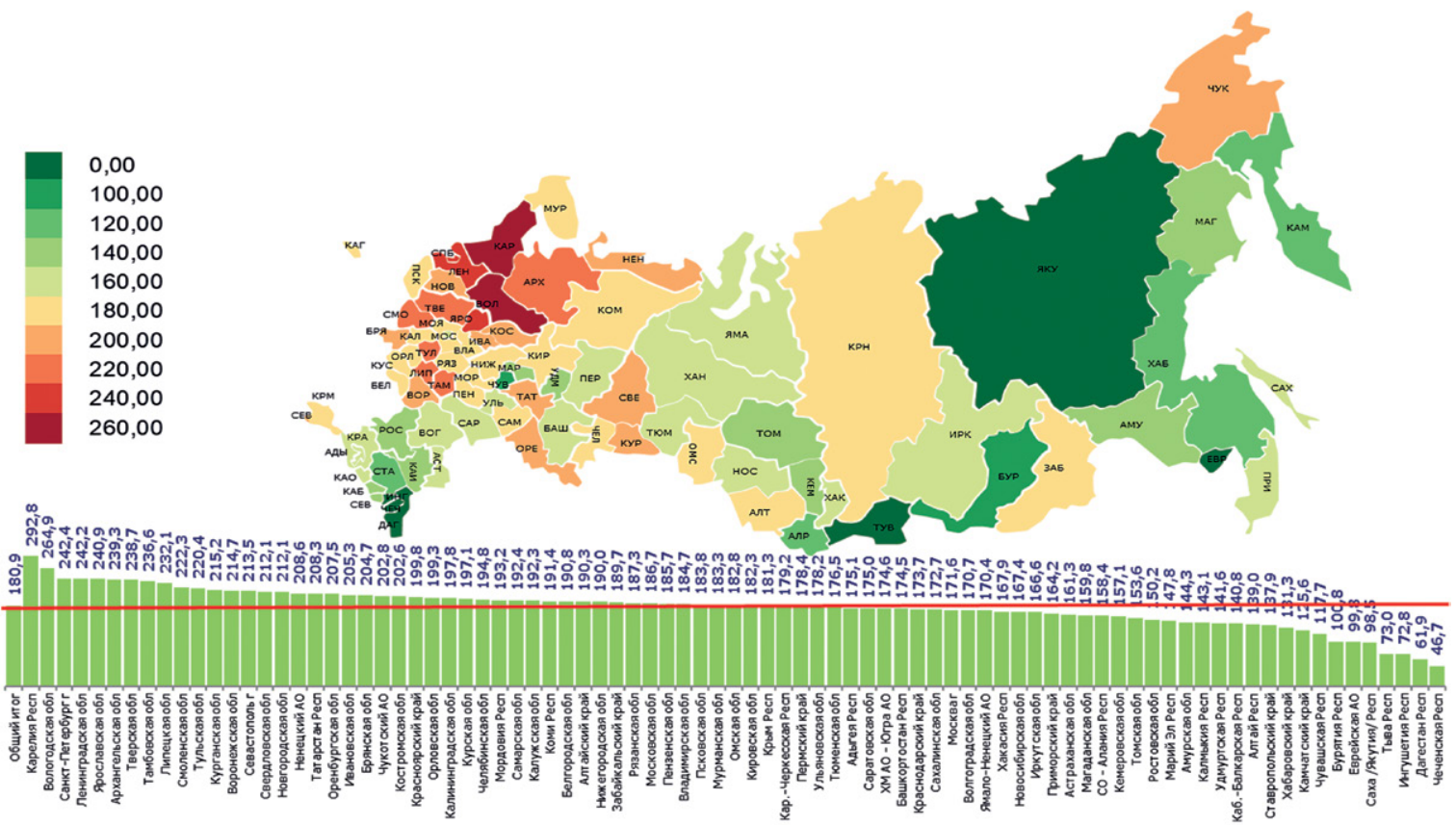

Рис. 2. Распространенность сахарного диабета 1 типа на 100 тыс. населения, 85 регионов Российской Федерации, 01.01.2021 г. (1 регион по данным Росстат).

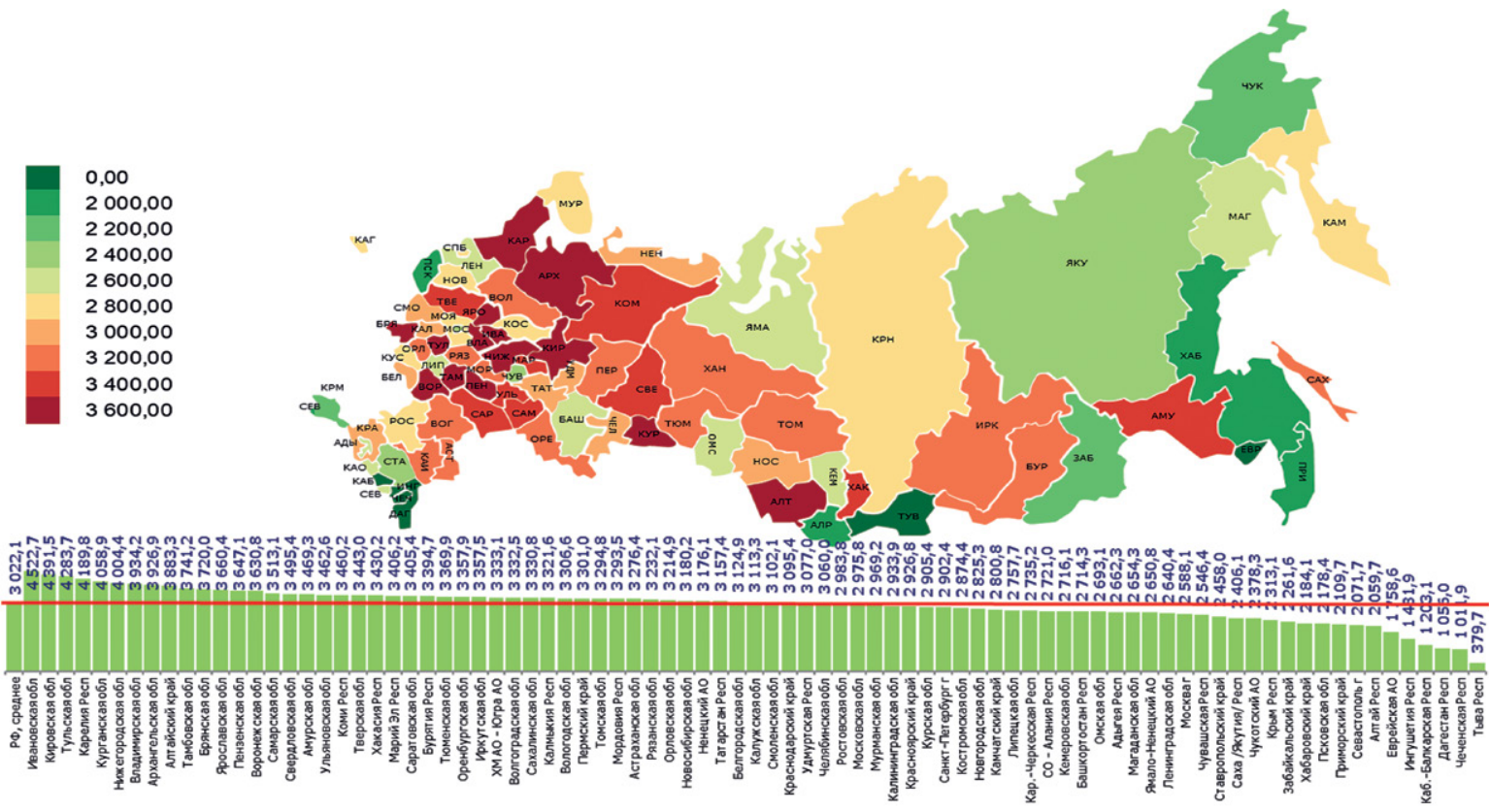

Рис. 3. Распространенность сахарного диабета 2 типа на 100 тыс. населения, 85 регионов Российской Федерации, 01.01.2021 г. (1 регион по данным Росстат).

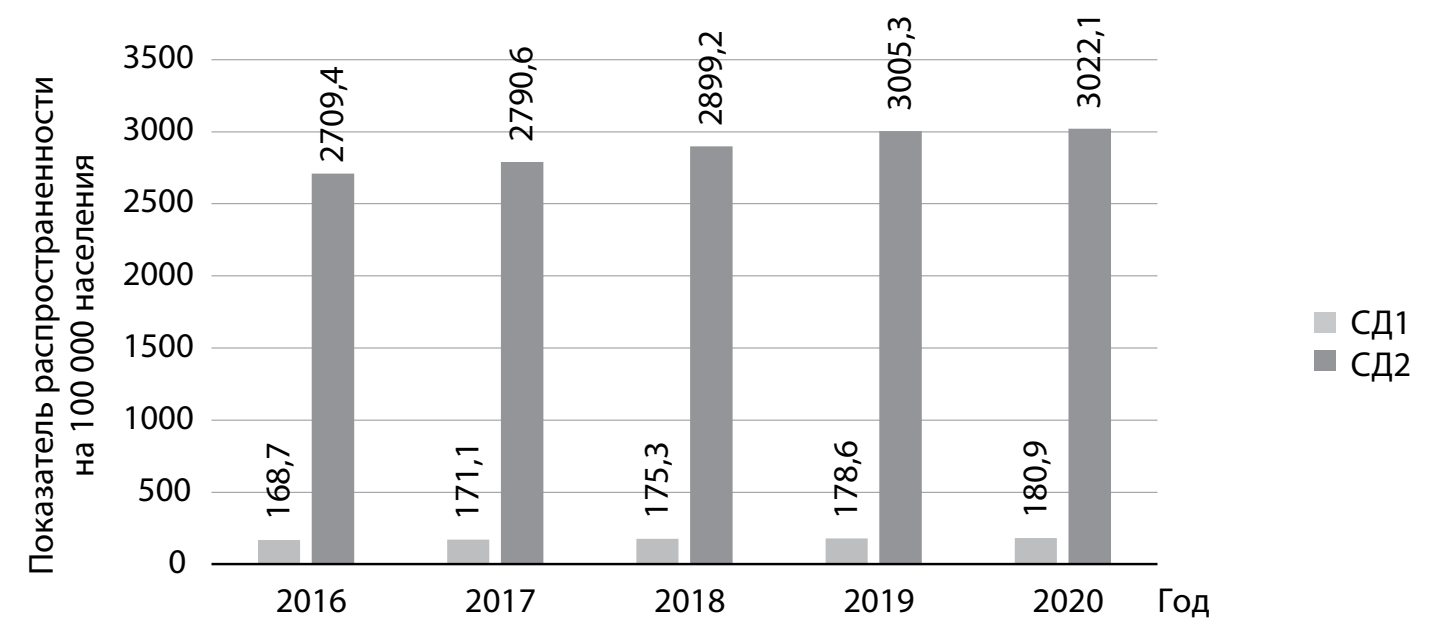

Рис. 4. Динамика распространенности сахарного диабета на 100 тыс. населения, 85 регионов Российской Федерации, 2016-2020 гг. 
СД 1

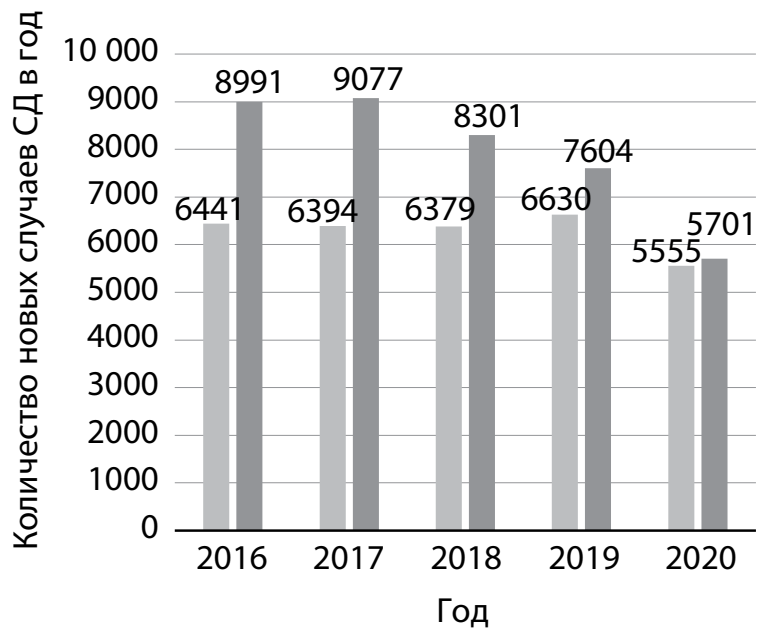

СД 2

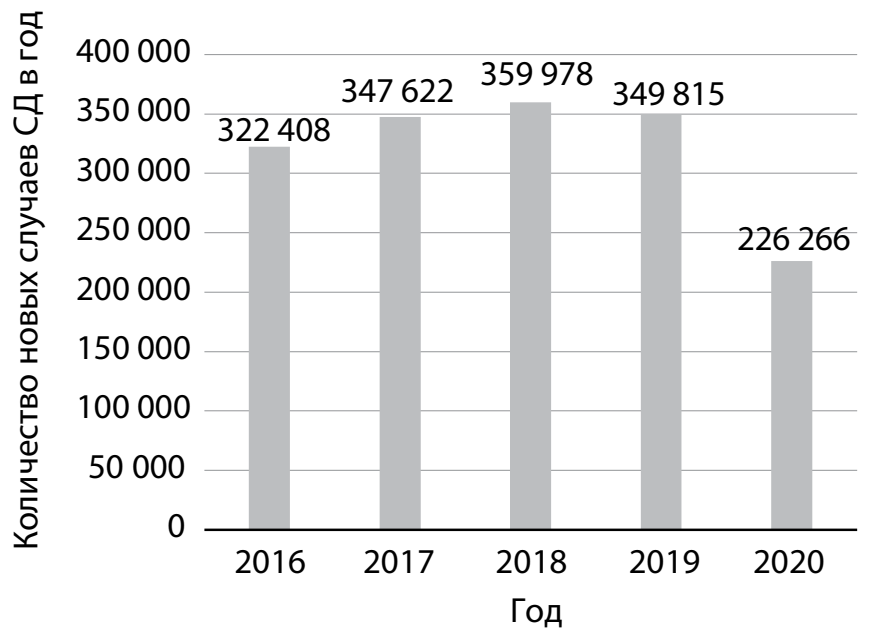

Дети до 18 лет в Взрослые

Рис. 5. Динамика заболеваемости сахарным диабетом в Российской Федерации, при сахарном диабете 1 типа выделены возрастные группы дети и подростки до 18 лет и взрослые, новые случаи сахарного диабета в год, 2016-2020 гг.

новых пациентов с СД2 и 10-15 тыс. пациентов с СД1 ежегодно (рис. 5). В 2020 г. впервые выявлено 11256 новых случаев СД1 и 226266 СД2, что по сравнению с 2016 г. составляет снижение на --20,9\% при СД1 и -35,3\% при СД2. В 2020 г. наблюдалось значительное снижение числа новых случаев впервые выявленного СД, что связано с изменением стандартной поликлинической работы на уровне первичного звена в условиях пандемии новой коронавирусной инфекции и самоизоляции пациентов. Снижение регистрации впервые выявленного СД может стать фактором ухудшения гликемического контроля, вероятности несвоевременного обучения пациента и, как следствие, - повышения риска развития осложнений в перспективе.

В последние 5 лет отмечается снижение количества новых «регистрируемых» случаев СД1 среди взрослых пациентов (рис. 5), возможно, обусловленное изменением кодирования. С одной стороны, это может быть связано со снижением заболеваемости среди взрослых пациентов при стабильных показателях у детей и подростков до 18 лет. Среди возможных причин - уменьшение неправильной регистрации СД2 на инсулинотерапии, которых относили в группу пациентов с СД1 с кодами E10, что зачастую отмечалось в более ранние периоды.

Данные по отдельным регионам представлены в приложении 2, табл. 1. Широкая вариабельность показателей заболеваемости СД в регионах свидетельствует о влиянии организационных факторов: работы по активному скринингу и выявлению СД в группах риска.

Клиническая характеристика пациентов с СД

в Российской Федерации

Половозрастные характеристики

Распределение по полу среди пациентов с СД в РФ представлено на рис. 6. При СД1: 54\% мужчин (143,6 тыс.) и 46\% женщин (121,8 тыс.), при СД2: 30\% мужчин (1 млн 331 тыс.) и 70,0\% женщин (3 млн 103 тыс.).

В распределении по возрасту при СД1 (рис. 7) отмечено постепенное возрастание доли пациентов с возраста 0-4 года с пиком распространенности в возрасте 30-39 лет (24,5\% мужчин и 21,8\% женщин) и наибольшим количеством пациентов в возрастных группах от 26 до 50 лет как у мужчин, так и у женщин $(52,7 \% / 75,6$ тыс. и 45,8\%/ 55,7 тыс. соответственно). При СД2 отмечено

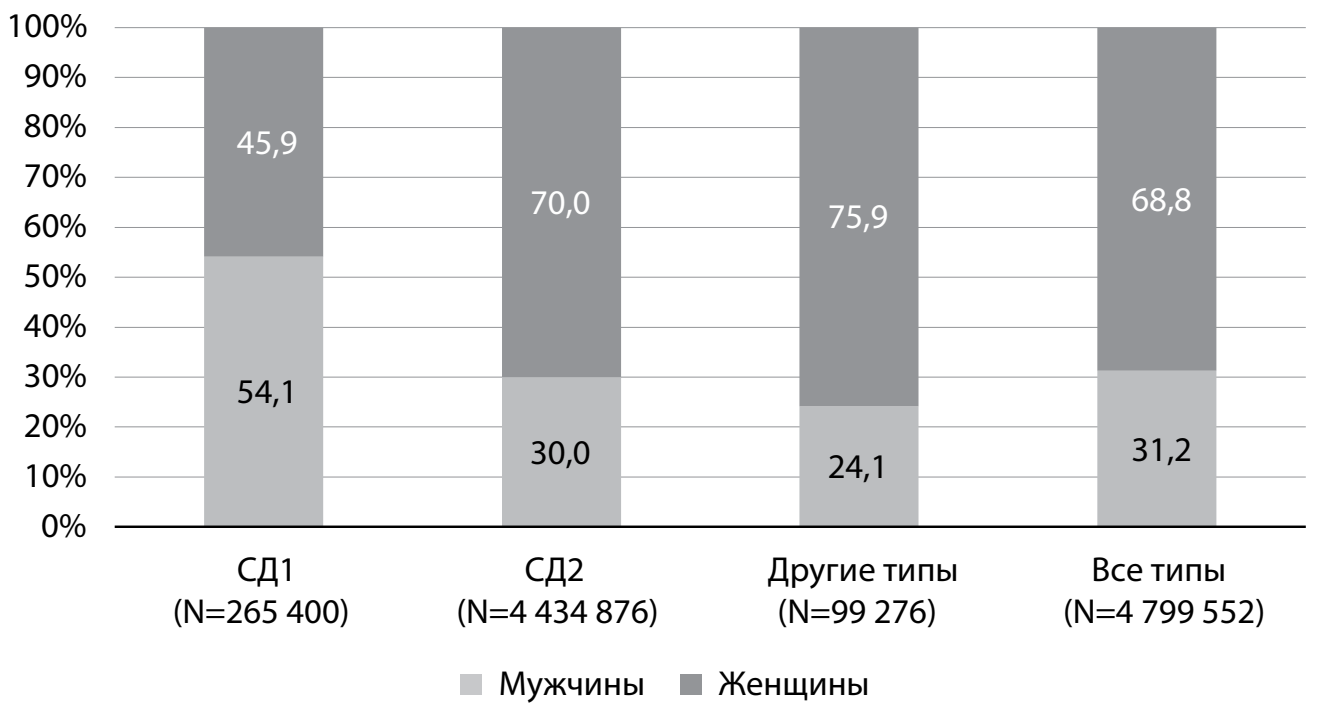

Рис. 6. Распределение по полу пациентов с сахарным диабетом в Российской Федерации, 01.01.2021. 


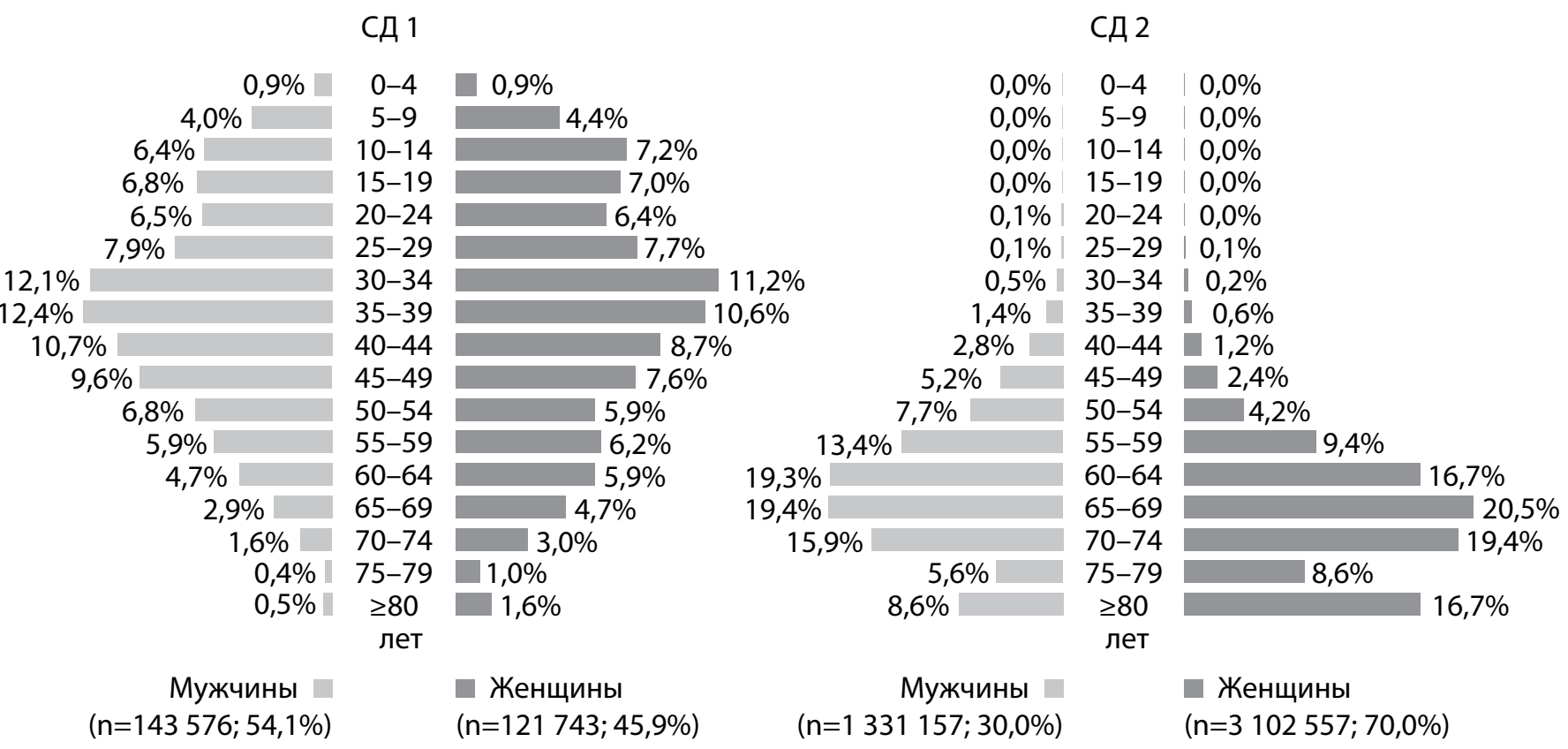

Рис. 7. Половозрастные характеристики пациентов с сахарным диабетом в Российской Федерации, 01.01.2021.

Таблица 1. Половозрастная характеристика пациентов старших возрастных групп

\begin{tabular}{lcccc|ccc}
\hline & & \multicolumn{3}{c|}{ СД 1 } & \multicolumn{2}{c}{ СД 2 } \\
\cline { 3 - 8 } Категория пациентов & $\begin{array}{c}\text { Всего, } \\
\text { человек }\end{array}$ & $\begin{array}{c}\text { всего, } \\
\text { человек }\end{array}$ & $\begin{array}{c}\text { \% всех } \\
\text { пациентов } \\
\text { с СД1 }\end{array}$ & $\begin{array}{c}\text { из них } \\
\text { мужчин, \% }\end{array}$ & $\begin{array}{c}\text { всего, } \\
\text { человек }\end{array}$ & $\begin{array}{c}\text { \% всех } \\
\text { пациентов } \\
\text { с СД2 }\end{array}$ & $\begin{array}{c}\text { из них } \\
\text { мужчин, \% }\end{array}$ \\
\hline Старше 65 лет & 2702177 & 20269 & $7,6 \%$ & $38,3 \%$ & 2681908 & $60,5 \%$ & $24,6 \%$ \\
Из них 80 лет и старше & 636139 & 2575 & $1,0 \%$ & $26,5 \%$ & 633564 & $14,3 \%$ & $18,1 \%$ \\
\hline
\end{tabular}

постепенное увеличение количества пациентов с возраста 30 лет с пиком распространенности в возрасте 65-69 лет у мужчин (19,4\%) и женщин (20,5\%) (рис. 7).

Характеристика пациентов старшей возрастной группы, включая когорту пациентов старше 80 лет, представлена в табл. 1. Общее количество пациентов старше 65 лет, по данным ФРСД на 01.01.2021, составило 2,7 млн, что составляет 7,6\% от общего количества пациентов с СД1 и 60,5\% -пациентов с СД2. Общее количество пациентов старше 80 лет 636,1 тыс., что составляет 1,0\% от общего количества пациентов с СД1 и 14,3\% - пациентов с СД2 (табл. 1).

Анализ смертности при сахарном диабете в Российской Федерации

В 2020 г. зарегистрировано 143323 случаев смерти пациентов с СД, из них:

- СД1: 2,7/100 тыс. населения, 3932 пациента (2,7\%), динамика с 2016 г. 3,0-2,7/100 тыс. населения, что составляет $-9,1 \%$;

- СД2: 93,9/100 тыс. населения, 137859 пациентов (96,2\%), динамика с 2016 г. 87,7-93,9/100. тыс. населения, что составляет $+0,7 \%$;

- другие типы СД: 1,0/100 тыс. населения, 1532 пациента (1,1\%).

Показатели смертности при СД в различных возрастных группах, по данным ФРСД по каждому из 85 регионов, представлены в Приложении 3, табл. 1.

Структура причин смерти пациентов с СД по данным ФРСД представлена на рис. 8. Среди причин смерти па- циентов с СД ведущие позиции продолжают занимать болезни системы кровообращения (БСК) $[6,7]$. Основной причиной смерти пациентов с СД являлись: инфаркт миокарда (ИМ), нарушения мозгового кровообращения (НMK), хроническая сердечно-сосудистая недостаточность и острые сердечно-сосудистые события (нарушения ритма, тромбоэмболия легочной артерии, тромбозы, внезапная сердечно-сосудистая смерть, кардиогенный шок, отек мозга), которые стали причиной смерти 38,1\% пациентов с СД1 и 52,0\% пациентов с СД2. Среди причин смерти, не связанных с СД, онкологическая патология сохраняет второе место после БСК в структуре смертности пациентов с СД 2 (10,1\%).

При этом доля пациентов, умерших от непосредственно диабетических причин, связанных с острыми и хроническими диабетическими осложнениями (комы, гангрены, терминальная стадия диабетического поражения почек), значительно ниже - суммарно 9,4\% при СД1 и 2,5\% при Сд2.

Динамика структуры причин смертности при обоих типах СД в 2016-2020 гг. представлена на диаграммах (рис. 9 и 10).

Отмечаются снижение доли умерших вследствие «истинных диабетических» причин: (диабетической комы (с 3,1 до 1,8\% при СД1, с 0,4 до 0,2\% при СД2) и относительно стабильный уровень смертности вследствие терминальной хронической почечной недостаточности (тХПН) (6,7-6,9\% при СД1 и 1,6-2,0\% при СД2). Отмечается увеличение доли умерших от старости при СД2 с 5,2 до 7,4\%, что отражает 


\section{СД $1 \mathrm{n}=3932$}

\section{Сердечно-сосудистые причины}

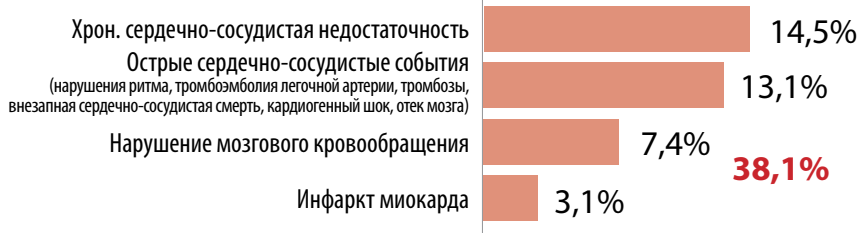

Острые и хронические диабетические осложнения

\begin{tabular}{r|c} 
Терминальная хроническая почечная & $6,9 \%$ \\
недостаточность & Диабетическая кома \\
Гангрена & $1,1 \%$ \\
Гипогликемическая кома & $0,7 \%$ \\
Сахарный диабет &
\end{tabular}

\begin{tabular}{|c|c|}
\hline \multicolumn{2}{|c|}{ Другие причины } \\
\hline Онкология & $4,9 \%$ \\
\hline Заболевания легких, органов дыхательной системы & $6,4 \%$ \\
\hline Коронавирус/осложнения коронавируса & $5,5 \%$ \\
\hline $\begin{array}{r}\text { Заболевания печени, поджелудочной железы, } \\
\text { органов ЖКТ }\end{array}$ & $5,5 \%$ \\
\hline Алкоголь, др. отравления & $3,3 \%$ \\
\hline Травмы & $1,8 \%$ \\
\hline Инфекция, сепсис & $2,1 \%$ \\
\hline Старость и дегенеративные заболевания & $0,8 \%$ \\
\hline Суицид & $0,9 \%$ \\
\hline Причина смерти не установлена & $7,6 \%$ \\
\hline
\end{tabular}

СД $2 \mathrm{n}=137859$

Сердечно-сосудистые причины

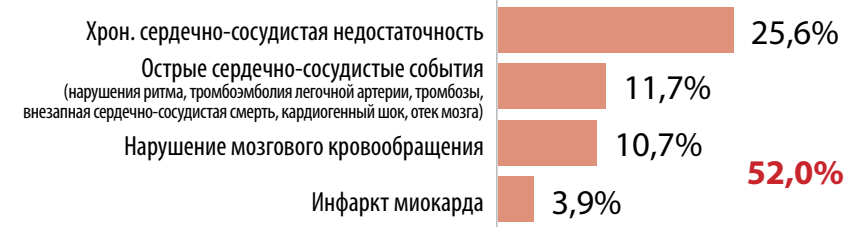

Острые и хронические диабетические осложнения

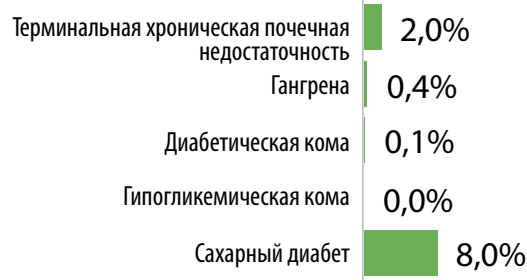

Другие причины

\begin{tabular}{|c|c|}
\hline Онкология & $10,1 \%$ \\
\hline Старость и дегенеративные заболевания & $7,4 \%$ \\
\hline Коронавирус/осложнения коронавируса & $5,1 \%$ \\
\hline Заболевания легких, органов дыхательной системы & $4,7 \%$ \\
\hline $\begin{array}{r}\text { Заболевания печени, поджелудочной железы, } \\
\text { органов ЖКТ }\end{array}$ & $2,9 \%$ \\
\hline Инфекция, сепсис & $0,9 \%$ \\
\hline Травмы & $0,8 \%$ \\
\hline Алкоголь, др. отравления & $0,4 \%$ \\
\hline Суицид & $0,2 \%$ \\
\hline Причина смерти не установлена & $5,0 \%$ \\
\hline
\end{tabular}

Рис. 8. Структура смертности пациентов с сахарным диабетом (по непосредственной причине смерти) по данным Федерального регистра пациентов с сахарным диабетом, 2020 г.

улучшение качества оказания медицинской помощи пациентам с СД, позволяющее дожить до естественной смерти.

В 2020 г. отмечается значительное увеличение доли умерших от других установленных причин смерти до 26,1\% при СД1 и 15,3\% при СД2 (рис. 9-10), что во многом обусловлено влиянием пандемии COVID-19. Так, при дополнительном анализе структуры этой графы при СД2 (рис. 11) было 5\% умерших от коронавируса/ его осложнений и отмечалось увеличение доли умерших от заболеваний органов дыхания в 2 раза - до 4,73\%, при этом доля других причин смерти в данном разделе не изменилась (рис. 11).

К сожалению, также увеличилась доля пациентов, у которых причина смерти указана как «сахарный диабет» без указания непосредственной причины смерти: по сравнению с 2016 г. данный показатель вырос при СД1 с 5,6 до 13,7\%, при СД2 - с 2,5 до 8,0\%. Данный факт не связан с истинным увеличением смертности пациентов от СД, а объясняется организационно-административными причинами, связанными с исполнением рекомендаций по кодированию смерти пациентов с СД - письмо Минздравсоцразвития РФ от 26.04.2011 N 14-9/10/2-4150 [8]. Согласно данному документу, в случае смерти пациента с СД от ИМ, острых форм цереброваскулярной болезни и сердечной недостаточности, первоначальной причиной смерти стали указывать СД, а острые формы ишемической и цереброваскулярной болезни - только его осложнениями, что значимо повлияло на структуру смертности. Тем не менее, доля БСК в структуре смертности пациентов с СД остается значи- тельной при обоих типах СД, практически без динамики за последние 5 лет (рис. 9 и 10).

Показатели среднего возраста смерти и длительность СД до момента смерти в 2016-2020 гг. у мужчин и женщин представлены в табл. 2. Отмечено увеличение длительности СД до момента смерти как у мужчин, так и у женщин: при СД1 с 17,4 до 19,1 года, при СД2 - с 11,0 до 11,4 года.

Учитывая факт неизбежности смерти по той или иной причине, возраст смерти становится ключевым критерием, отражающим успешность мер, направленных на снижение смертности.

При анализе возраста смерти становится очевидной выраженная диссоциация в зависимости от причины смерти при обоих типах СД.

Так, средний возраст смерти при СД1 без учета пола составляет 53,2 года (табл. 2, рис. 12). В более старшем возрасте фиксируется смерть от таких причин, как старость и дегенеративные заболевания (средний возраст смерти 70,0 года), хронической сердечно-сосудистой недостаточности (60,8 года), ИМ (59,3 года), онкологии (57,9 года) и НМК (56,4 года). Ниже черты среднего возраста смерти при СД1 находятся причины, связанные с неудовлетворительным контролем СД: диабетические комы (40,6 года), гипогликемические комы (41,0 года), а также инфекции, сепсис (42,1 года). И наиболее «молодой возраст смерти» отмечался по причинам, которые можно классифицировать как следствие социальных факторов: алкоголь (42,2 года), суицид (43,3 года) и травмы (45,5 года).

При СД2 (рис. 13) старше среднего возраста смерти в 73,5 года находились такие причины, как старость 


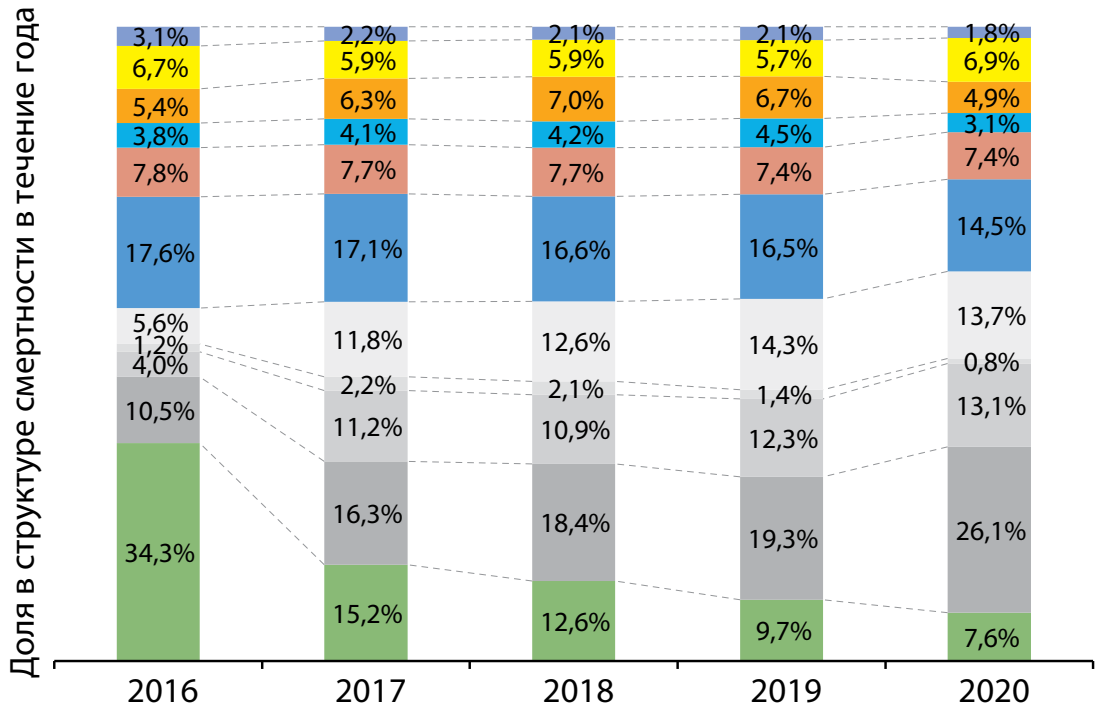

- Диабет. кома

тХПН

- Онкология

- Инфаркт миокарда

- HMK

- Хроническая сердечно-сосудистая недостаточность

СД

1- Старость

- Острые ССС

- Другие установленные причины

- Причина не установлена

Рис. 9. Динамика структуры причин смерти при сахарном диабете 1 типа 2016-2020 гг. по данным Федерального регистра пациентов с сахарным диабетом (ТХПН - терминальная хроническая почечная недостаточность; НМК — нарушение мозгового кровообращения; СД - сахарный диабет; ССС - сердечно-сосудистые события).
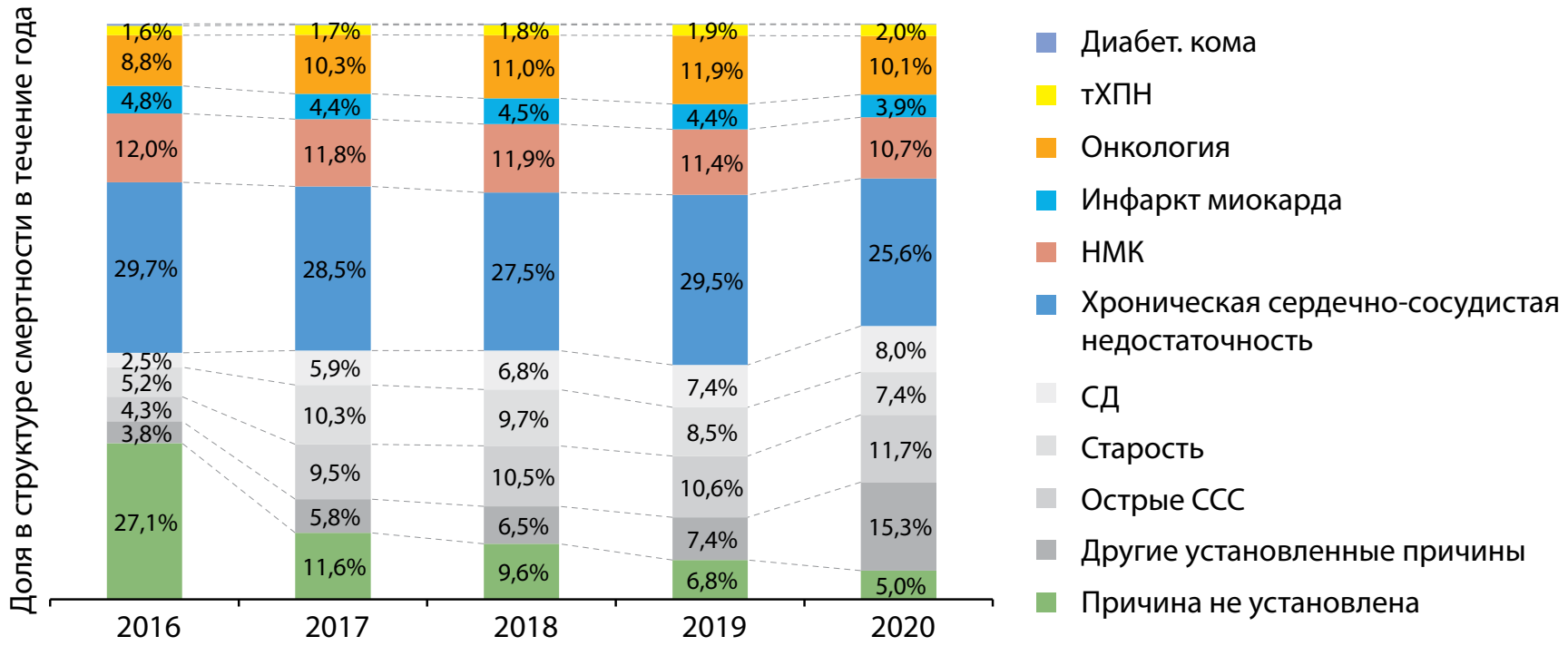

Рис. 10. Динамика структуры причин смерти при сахарном диабете 2 типа 2016-2020 гг. по данным Федерального регистра пациентов с сахарным диабетом (тХПН - терминальная хроническая почечная недостаточность; НMК -нарушение мозгового кровообращения; СД - сахарный диабет; ССС - сердечно-сосудистые события).

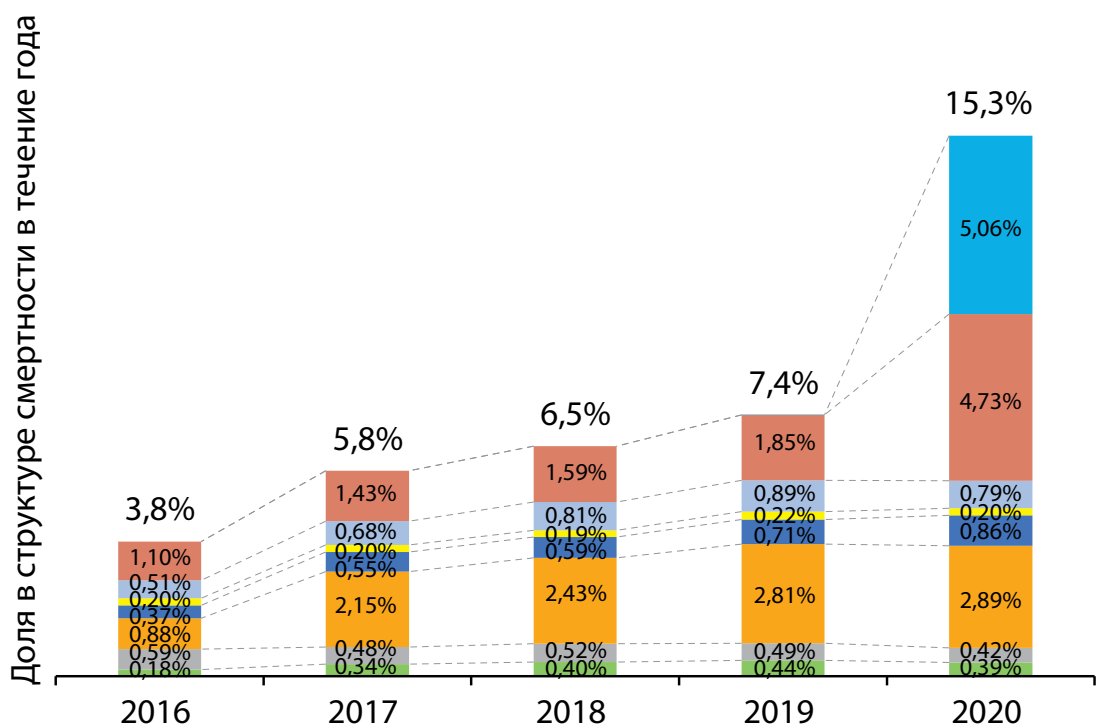
- Коронавирус/осложнения коронавируса
- Заболевания легких, органов дыхательной системы
Травмы
Суицид
- Инфекции, сепсис
— Заболевания печени, поджелудочной железы, органов ЖКТ
- Гангрена
- Алкоголь, др. отравления

Рис. 11. Динамика структуры других установленных причин смерти при сахарном диабете 2 типа 2016-2020 гг. 
Таблица 2. Средний возраст смерти пациентов с сахарным диабетом 1 и 2 типов по данным Федерального регистра пациентов с сахарным диабетом, 2016-2020 гг.

\begin{tabular}{|c|c|c|c|c|c|c|c|c|c|c|c|}
\hline \multirow{2}{*}{\multicolumn{2}{|c|}{ Показатель }} & \multicolumn{5}{|c|}{ СД 1} & \multicolumn{5}{|c|}{ СД 2} \\
\hline & & 2016 & 2017 & 2018 & 2019 & 2020 & 2016 & 2017 & 2018 & 2019 & 2020 \\
\hline \multirow{5}{*}{$\begin{array}{l}\text { Средний } \\
\text { возраст } \\
\text { смерти, лет }\end{array}$} & Женщины & 58,7 & 58,4 & 58,4 & 57,7 & 55,2 & 75,7 & 76,2 & 76,1 & 76,0 & 75,4 \\
\hline & & & & & & & & & & & \\
\hline & Мужчины & 50,7 & 50,7 & 50,5 & 50,9 & 50,5 & 70,2 & 70,5 & 70,4 & 70,3 & 70,1 \\
\hline & & & & & & & & & & & \\
\hline & Все пациенты & 53,9 & 53,8 & 53,5 & 53,6 & 52,3 & 73,9 & 74,3 & 74,2 & 74,1 & 73,5 \\
\hline \multirow{4}{*}{$\begin{array}{l}\text { Длительность } \\
\text { СД } \\
\text { до момента } \\
\text { смерти, лет }\end{array}$} & Женщины & 20,1 & 20,8 & 21,8 & 22,7 & 22,3 & 11,8 & 12,2 & 12,3 & 12,3 & 12,3 \\
\hline & Мужчины & 15,6 & 15,9 & 16,4 & 16,7 & 17,1 & 9,2 & 9,5 & 9,5 & 9.5 & 9,6 \\
\hline & 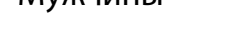 & & & & & & & & & & \\
\hline & Все пациенты & 17,4 & 17,9 & 18,4 & 19,0 & 19,1 & 11,0 & 11,3 & 11,4 & 11,4 & 11,4 \\
\hline
\end{tabular}

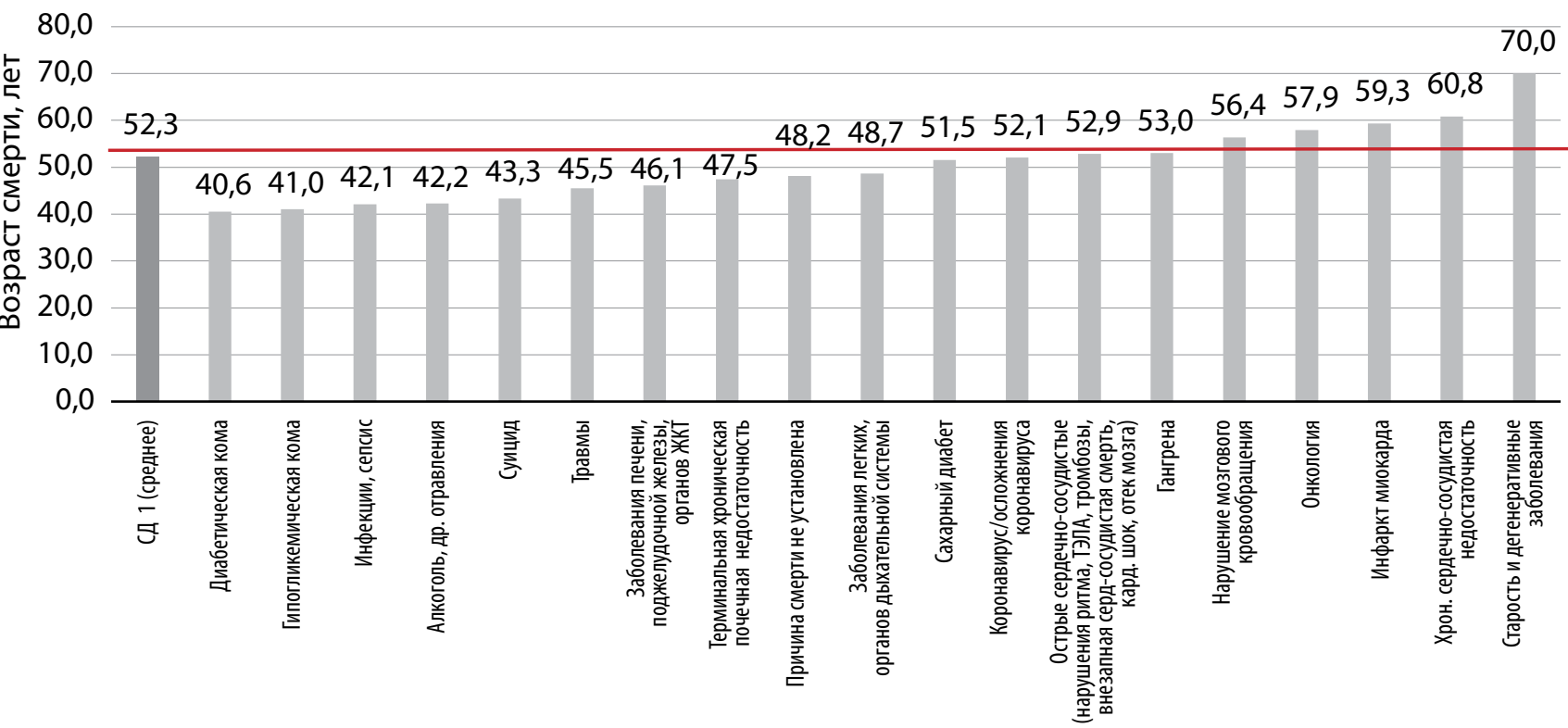

Рис. 12. Фактическая продолжительность жизни (средний возраст смерти) при сахарном диабете 1 типа в зависимости от причины смерти, 2020 г. по данным Федерального регистра пациентов с сахарным диабетом.

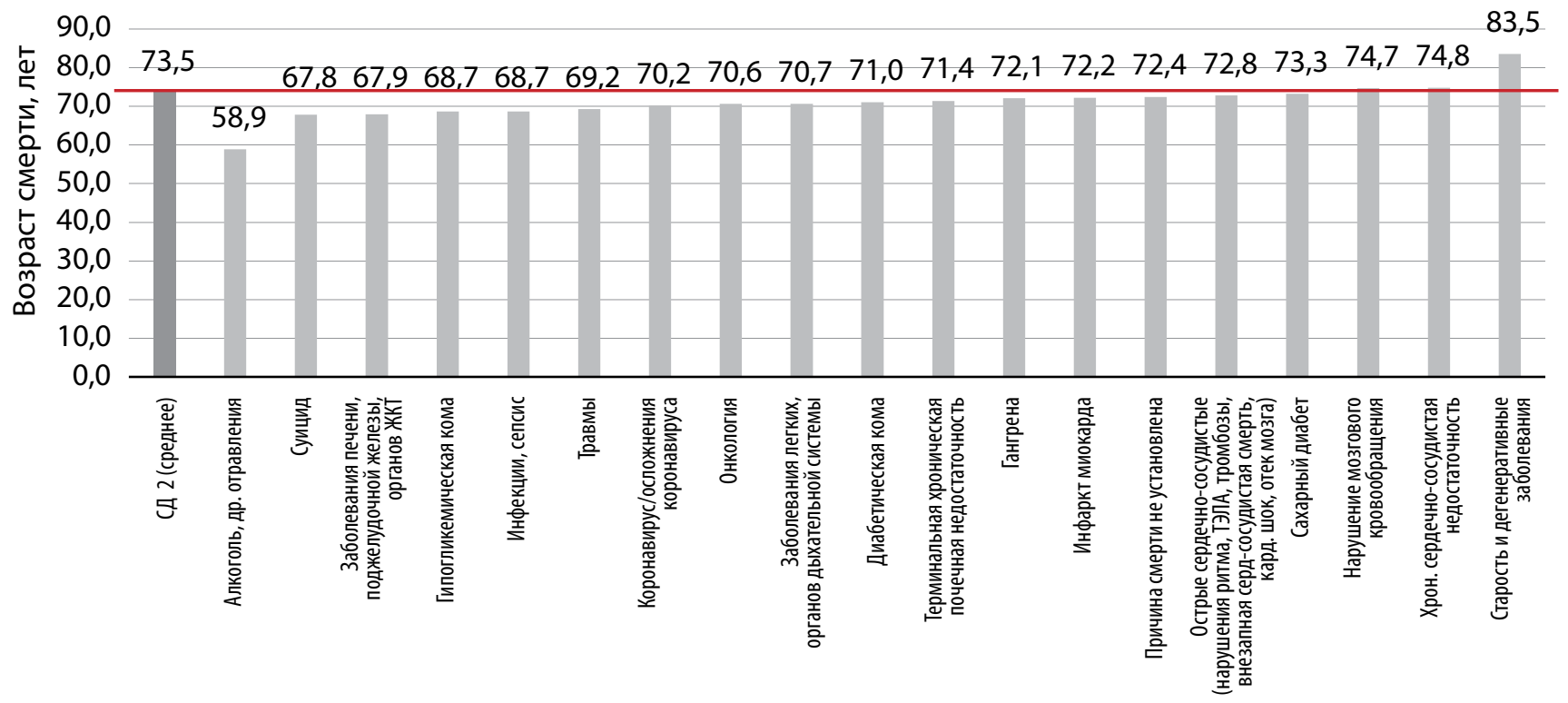

Рис. 13. Фактическая продолжительность жизни (средний возраст смерти) при сахарном диабете 2 типа в зависимости от причины смерти, 2020 г., по данным Федерального регистра пациентов с сахарным диабетом. 


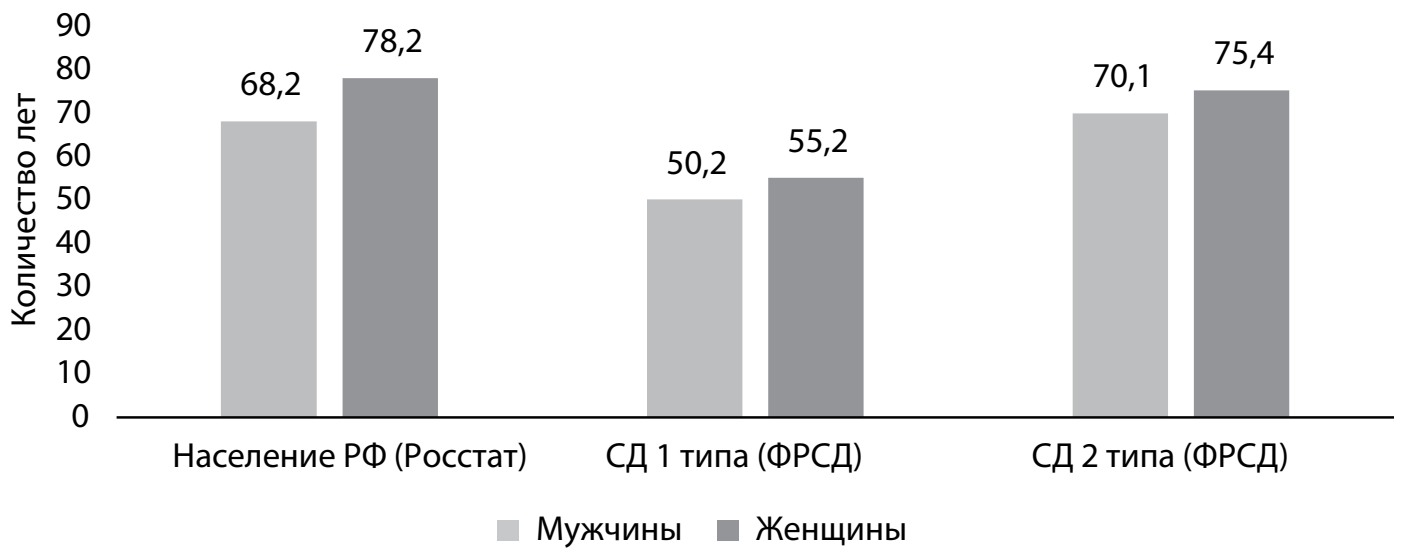

Рис. 14. Фактическая продолжительность жизни (средний возраст смерти). Данные Росстат (общая популяция, 2019 г.) и Федерального регистра пациентов с сахарным диабетом 2020 г.

и дегенеративные заболевания (83,5 года), хроническая сердечно-сосудистая недостаточность (74,8 года) и НМК (74,7 года). Возраст смерти от ИМ - 72,2 года, от гангрены - 72,1 года. Возраст смерти от диабетических причин вследствие острых (комы) и хронических осложнений (тХПН), как и при СД1, был ниже среднего возраста смерти, наиболее «молодой возраст смерти» - в группе социальных причин.

По последним имеющимся данным Росстат, средняя продолжительность жизни в общей популяции составляет у мужчин 68,2 года, у женщин - 78,2 года (рис. 14) [9]. Таким образом, фактическая продолжительность жизни пациентов с СД2 сопоставима со средними показателями общей популяции без СД2 (рис.14).

Анализ распространенности осложнений при сахарном диабете в Российской Федерации

Регистр позволяет оценивать распространенность осложнений СД и их стадию. Наибольшая частота отмечается у микрососудистых осложнений: диабетиче- ская нейропатия (ДН) - 43,3\% и 24,4\% при СД1 и СД2, диабетическая нефропатия, хроническая болезнь почек (ХБП) - 25,9\% и 18,4\%, диабетическая ретинопатия (ДР) $-31,7 \%$ и 13,5\% соответственно (рис. 15).

В отношении макрососудистых осложнений, для которых характерно многофакторное развитие, отмечена относительно меньшая частота: при СД1/СД2 частота ИБС 2,5\%/10,1\%, ИМ - 1,0\%/3,5\%. Однако учитывая общую численность пациентов с СД2 более 4,4 млн, количество пациентов с сердечной недостаточностью, атеросклеротическими сердечно-сосудистыми заболеваними (СС3) и ХБП превышает 1,7 млн. Стоит учитывать, что в регистре фиксируются только верифицированные диагнозы, поэтому в отсутствие специализированного обследования истинная частота может недооцениваться [10]. Так, при активном скрининге по данным Диамодуля, частота СС3 в 1,5-2 раза выше, несмотря на тенденции к положительной динамике по сравнению с периодом выездов в 2000-х гг. в рамках Федеральной целевой программы (ФЦП) [10].

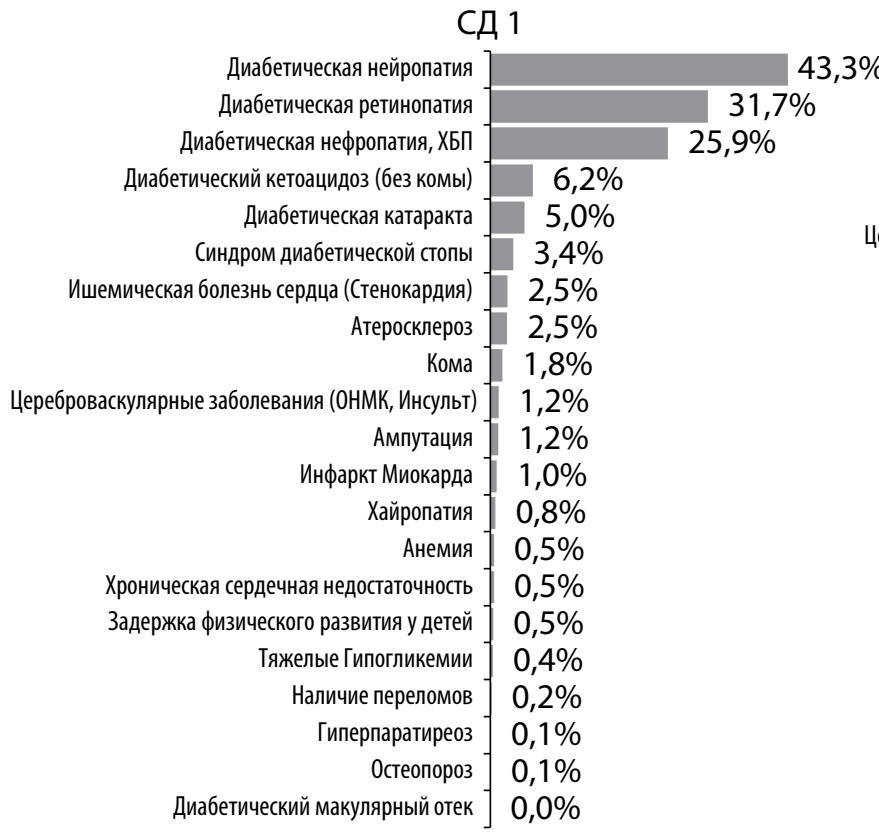

\begin{tabular}{|c|c|}
\hline \multicolumn{2}{|c|}{ СД 2} \\
\hline Диабетическая нейропатия & $24,4 \%$ \\
\hline Диабетическая нефропатия, ХБП & $18,4 \%$ \\
\hline Диабетическая ретинопатия & $13,5 \%$ \\
\hline Ишемическая болезнь сердца (Стенокардия) & $10,1 \%$ \\
\hline Атеросклероз & $4,4 \%$ \\
\hline ереброваскулярные заболевания (ОНМК, Инсульт) & $4,2 \%$ \\
\hline Диабетическая катаракта & $4,1 \%$ \\
\hline Инфаркт Миокарда & $3,5 \%$ \\
\hline Диабетическая макроангиопатия & $2,8 \%$ \\
\hline Хроническая сердечная недостаточность & $2,4 \%$ \\
\hline Синдром диабетической стопы & $1,5 \%$ \\
\hline Ампутация & $0,8 \%$ \\
\hline Диабетический кетоацидоз (без комы) & $0,4 \%$ \\
\hline Анемия & $0,2 \%$ \\
\hline Наличие переломов & $0,1 \%$ \\
\hline Хайропатия & $0,1 \%$ \\
\hline Остеопороз & $0,1 \%$ \\
\hline Кома & $0,1 \%$ \\
\hline Гиперпаратиреоз & $0,1 \%$ \\
\hline Тяжелые Гипогликемии & $0,0 \%$ \\
\hline Задержка физического развития у детей & $0,0 \%$ \\
\hline Диабетический макулярный отек & $0,0 \%$ \\
\hline
\end{tabular}

Рис. 15. Распределение частоты осложнений при сахарном диабете 1 и 2 типов в Российской Федерации на 01.01 .2021 (при сахарном диабете 1 типа $\mathrm{n}=265$ 400, при сахарном диабете 2 типа $-\mathrm{n}=4434$ 876). 


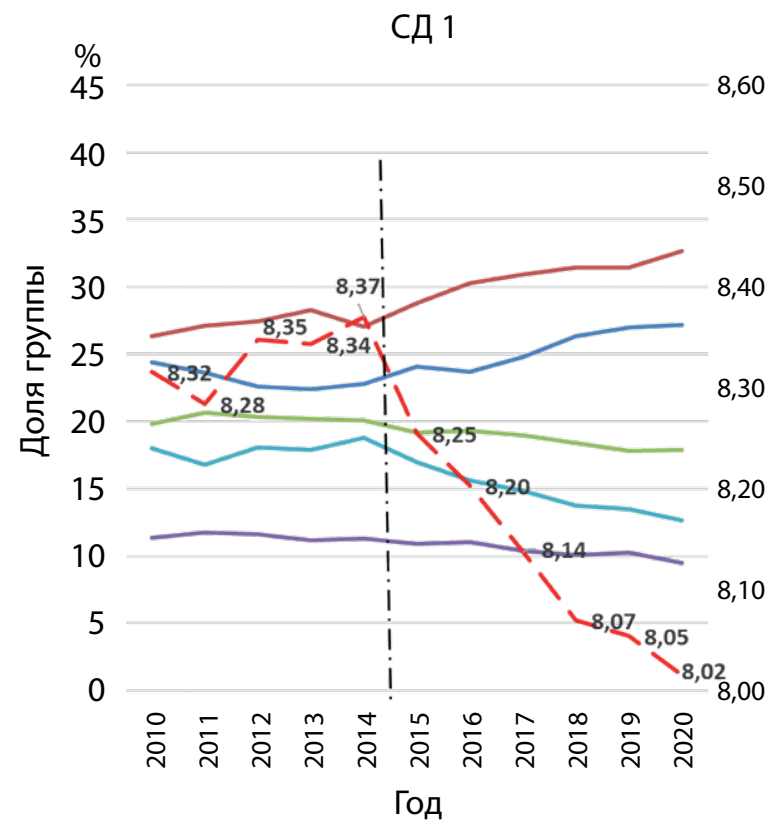

— до 7 - от 7 до 7,9 - от 8 до 8,9
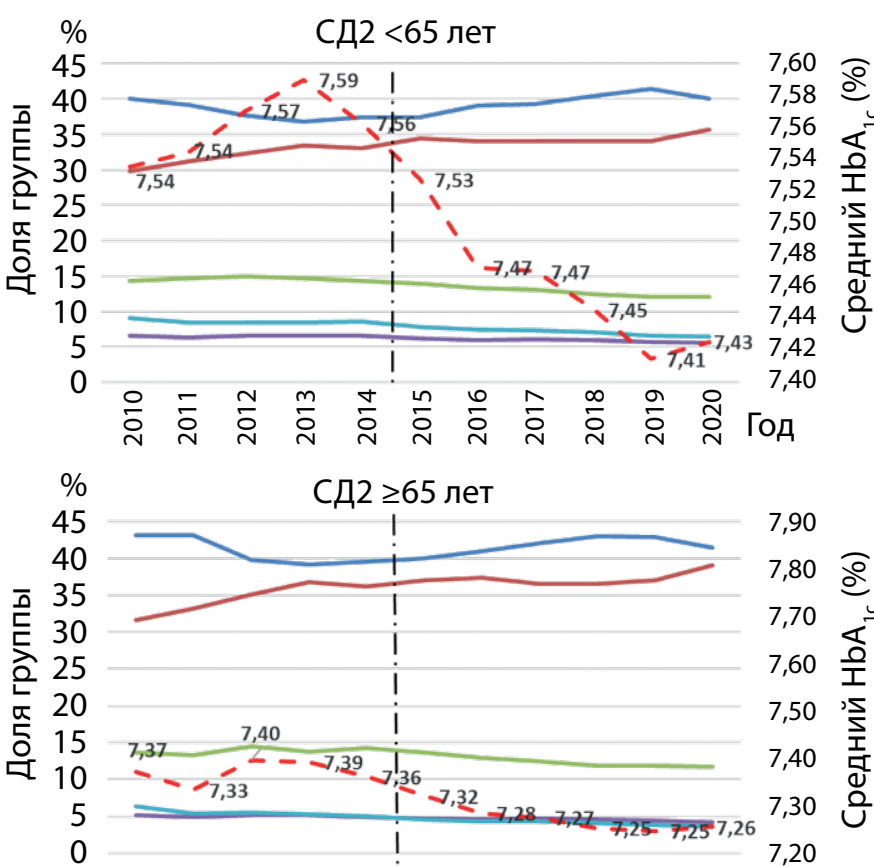

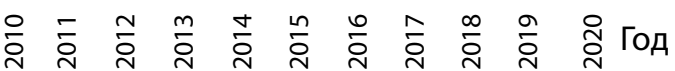

Рис. 16. Динамика гликированного гемоглобина $\left(\mathrm{HbA}_{1 c}\right)$ у пациентов с сахарным диабетом по данным Федерального регистра пациентов с сахарным диабетом в Российской Федерации 2010-2020 гг. С 2014 года начат дополнительный расчет НbА 1 по данным глюкозы (отмечено вертикальной пунктирной линией).

Основную угрозу представляют терминальные стадии диабетических осложнений. За последние годы отмечается положительная динамика уменьшения частоты терминальных стадий ДР (слепоты) и ХБП (диализ), а также доли высоких ампутаций [11]. В анализируемый период 2016-2020 гг. данные тенденции сохраняются: отмечается снижение

- слепоты при СД1 с 105,9 до 94,0/10 000 взрослых пациентов; при СД2 - с 17,6 до 15,3/10 000 взрослых пациентов;

- частоты ампутаций нижних конечностей при СД1 с 140,6 до 134,3/10 000 взрослых пациентов; при СД2 - с 79,0 до 76,7/10 000 взрослых пациентов;

- ТХПН при СД1 с 147,05 до 137,65/10 000 взрослых пациентов; при СД2 - с 25,83 до 20,16/10 000 взрослых пациентов.

\section{Анализ состояния компенсации углеводного обмена (уровня $\mathrm{HbA}_{1 c}$ )}

Для клинической практики уровень гликированного гемоглобина $\left(\mathrm{HbA}_{1 c}\right)$ является показателем, определяющим оценку ССТ, абсолютно необходимым для принятия решения о ее эффективности или необходимости интенсификации.

Мы провели анализ динамики контроля углеводного обмена по среднему уровню $\mathrm{HbA}_{1 с}$ при СД1 и СД2 в период 2010-2020 гг. (рис. 16). Отмечена положительная динамика средних значений при обоих типах СД: при СД1 - с 8,51\% до 8,05\%, при СД2 в возрасте <65 лет с 7,54\% до 7,43\%, и при СД2 в возрасте $>65$ лет - 7,37\%7,26\%.

Распределение пациентов по диапазонам $\mathrm{HbA}_{1 c}$ на 01.01.2021 составило:
СД 1

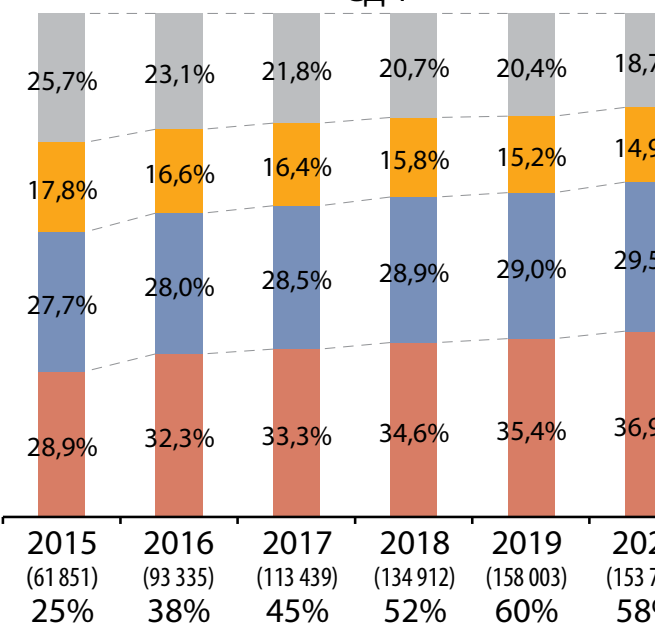

СД 2

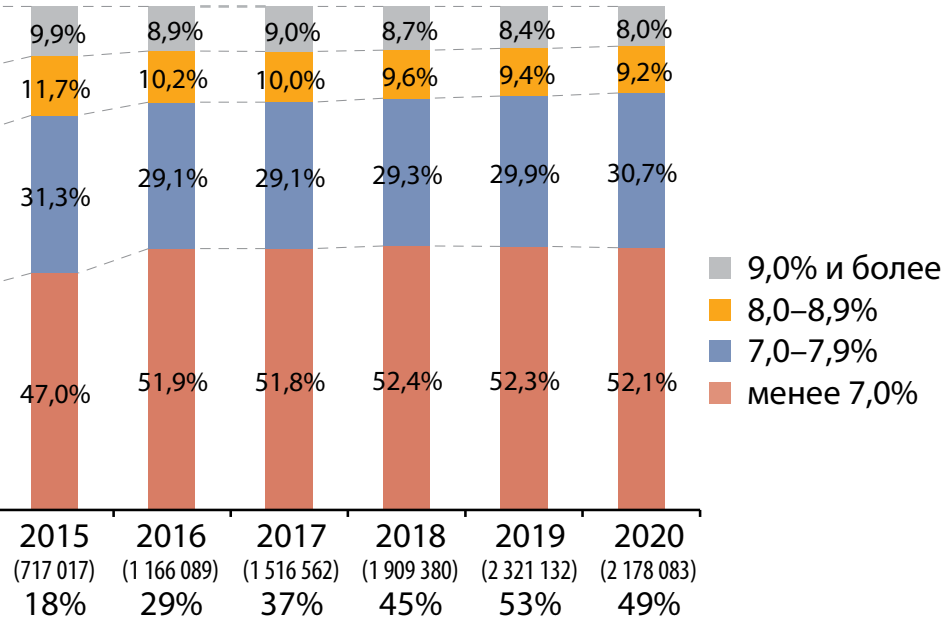

Рис. 17. Клинический статус пациентов с сахарным диабетом: гликированный гемоглобин ( $\left.\mathrm{bbA}_{1 с}\right), 84$ региона Российской Федерации, все возрастные группы, 2015-2020 гг. 


\begin{tabular}{|c|c|c|c|c|c|c|c|}
\hline & & & & & & & \\
\hline Статус HbA1c* & Измерялся & $\checkmark$ & Инд. целевой HbAlc & 7.0 & $\checkmark$ & \% недостижения HbA1c & $\sqrt{1,0-2,4 \%}$ \\
\hline НbA1c (1 квартал). & 8,0 & & НbА1с (2 квартал). & & & HbA1c (3 квартал), 96 & \\
\hline$\%$ & & & $\%$ & & & & \\
\hline
\end{tabular}

\begin{tabular}{|c|c|c|c|c|c|c|c|}
\hline Cтатус HbA1c* & Измерялся & $\checkmark$ & Инд. целевой HbAlc & 7,0 & $\checkmark$ & 96 недостижения $\mathrm{HbA1c}$ & Достигнул \\
\hline HbA1c (1 квартал). & 8,0 & & НbA1c (2 квартал), & 7.0 & & НbA1c (3 квартал), \$ & \\
\hline$\%$ & & & 9 & & & & \\
\hline
\end{tabular}

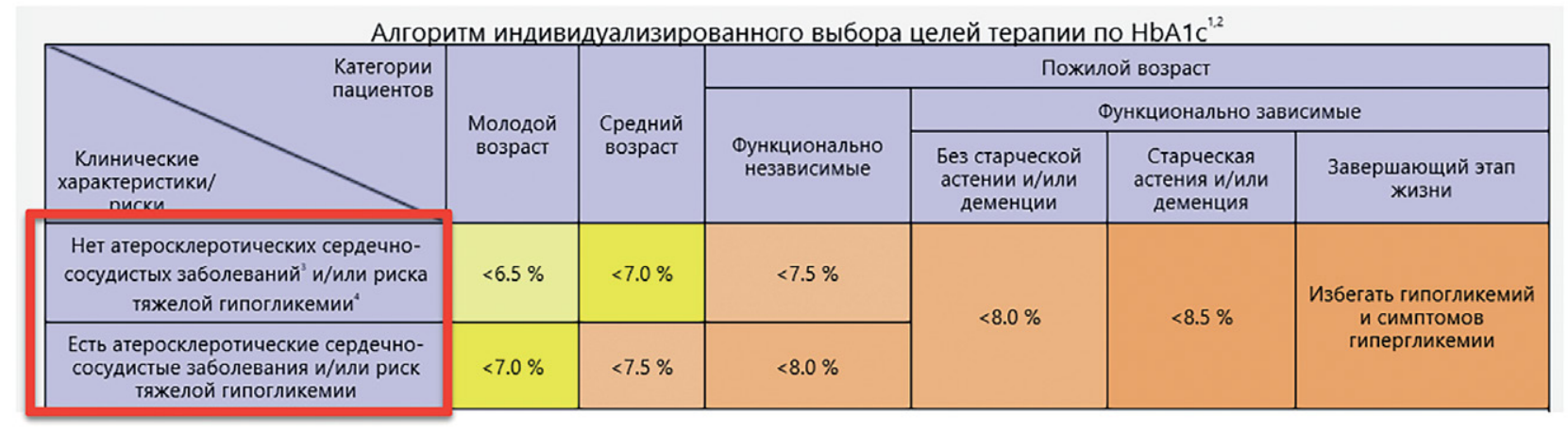

Рис. 18. Изображение диалогового окна регистра в разделе внесения данных гликированного гемоглобина (НbА1с) с возможностью выбора индивидуального целевого уровня и автоматическим расчетом процента недостижения цели.

- при СД1:уровень $\mathrm{HbA}_{1 c}<7 \%-36,9 \%$ пациентов, в диапазоне 7-7,9\% - 29,5\% пациентов, 8-8,9\%-14,9\% пациентов, $\geq 9,0 \%-18,7 \%$ пациентов;

- при СД2: уровень $\mathrm{HbA}_{1 c}<7 \%-52,1 \%$ пациентов, в диапазоне 7-7,9\% - 30,7\% пациентов, 8-8,9\% - 9,2\% пациентов, $\geq 9,0 \%-8,0 \%$ пациентов (рис. 17).

Следует отметить несомненно положительную динамику охвата пациентов исследованием $\mathrm{HbA}_{1 с}$ в период 2015-2020 гг.: при СД1 - с 25\% до 58\%, при СД2 - с 18\% до более 49\% (рис. 17). Тем не менее, согласно «Алгоритмам специализированной медицинской помощи больным сахарным диабетом», уровень $\mathrm{HbA}_{1 с}$ необходимо оценивать у всех пациентов с СД [12], при этом в настоящий момент, согласно ФРСД, $\mathrm{HbA}_{1 c}$ регистрируется только у половины пациентов. Создается впечатление, что оценка $\mathrm{HbA}_{1 c}$ по обращаемости происходит у более активной, а соответственно, и более сохранной части пациентов. Так, по данным обследования в Диамодуле, когда исследование $\mathrm{HbA}_{1 c}$ проводится у 100\% пациентов, показатели соответствуют целевому уровню лишь у 25-28\% пациентов с СД2 и 11,7-13,7\% пациентов при СД1, что почти в 3 раза меньше по сравнению с данными регистра [13].

Выбор индивидуальных целей лечения зависит от множества факторов (возраста пациента, ожидаемой продолжительности жизни, наличия СС3 и факторов риска тяжелых гипогликемий) [12]. В настоящее время в ФРСД введены элементы системы поддержки принятия решений, а именно - автоматический калькулятор расчета недостижения цели $\mathrm{HbA}_{1 c}$ (рис. 18). Для большинства взрослых пациентов с СД целевым является уровень $\mathrm{HbA}_{1 c}<7,0 \%$ [12], но можно установить более жесткие критерии. Изменилась возможность кратности ввода показателя: не 1 раз в год, а ежеквартально, как требуют клинические рекомендации. Существует и автоматический отчет, включающий не только средний уровень
$\mathrm{HbA}_{1 c^{\prime}}$ но и соотношение по диапазонам и поквартальную динамику данного показателя, который может сделать каждый врач, руководитель ЛПУ и главный специалист региона на конкретной когорте пациентов. Таким образом, регистр является не только системой внесения данных, но и руководством к выбору индивидуальных целевых параметров гликемического контроля в зависимости от клинического статуса пациента.

Обучение пациентов является неотъемлемой частью комплекса терапевтических мероприятий, направленных на достижение целевого гликемического контроля. Клинические рекомендации позиционируют необходимость обучения в дебюте СД и его продолжения на всем протяжении заболевания $[14,15]$. Однако данные анализа ФРСД свидетельствуют, что самоконтроль не проводят около трети пациентов с СД2 (32\%) и 6\% с СД1, а обучение в «Школе для пациентов с СД» проходят только 46\% пациентов с СД2 и 71\% - с СД1 (рис. 19 и 20), что, несомненно, является лимитирующим фактором достижения целевого контроля.

\section{Анализ структуры медикаментозной терапии сахарного диабета}

После перехода регистра в онлайн-формат стала возможна оценка структуры ССТ в РФ, что является важнейшим инструментом для анализа назначения антидиабетических препаратов. Эти данные можно рассматривать в качестве основы для оптимизации алгоритмов терапии в реальной клинической практике.

Структура ССТ при СД2 в РФ на 01.01.2021 г. представлена на рис. 21. Установлено, что в структуре медикаментозной терапии СД2 преобладает назначение пероральных сахароснижающих препаратов (ССП) - у 76,2\% пациентов, преимущественно в монотерапии - 44,1\% пациентов; комбинацию 2 ССП получают 28,9\% пациентов, 3 препаратов - 3,2\% пациентов (рис. 21). Количество 


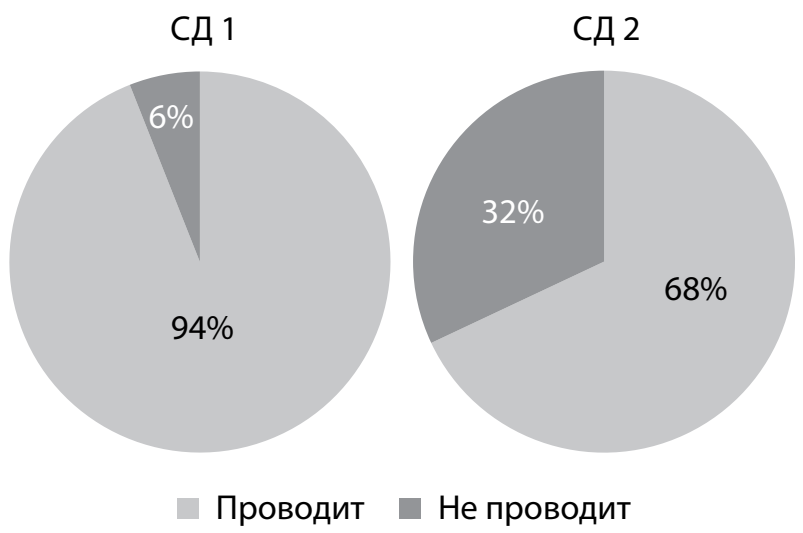

Рис. 19. Данные Федерального регистра пациентов с сахарным диабетом по проведению самоконтроля, параметр указан при сахарном диабете 1 типа у 90,9\%, при сахарном диабете 2 типа у 82,1\% пациентов на 01.01.2021.

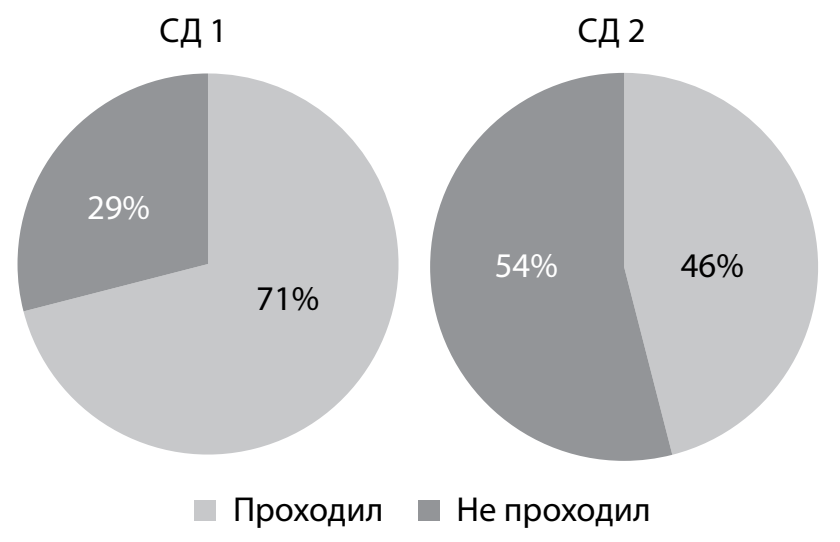

Рис. 20. Данные Федерального регистра пациентов с сахарным диабетом по обучению пациентов с сахарным диабетом в школе диабета, параметр указан при сахарном диабете 1 типа у 46,9\%, при сахарном диабете 2 типа у 38,3\% пациентов на 01.01.2021.
ССп

(Сахароснижающие препараты)

$\mathbf{7 6 , 2} \%$

Инсулинотерапия

$18,8 \%$

$\begin{aligned} & \text { Немедикаментозная } \\ & \text { терапия } \\ & \mathbf{4 , 9 \%}\end{aligned}$
3,0\%
$1,9 \%$

Рис. 21. Структура сахароснижающей терапии сахарного диабета 2 типа в Российской Федерации на 01.01.2021 г.
Монотерапия

Комбинация 2 ССП

Комбинация 3 и более ССП

Комбинация инсулина и ССП

Только инсулины

Терапия не указана

Диета пациентов с СД2 на инсулинотерапии составило 18,8\%, из которых 11,3\% пациентов получали комбинированную терапию инсулинами в сочетании с различными ССП и 7,5\% - только инсулинами, 1,9\% пациентов находились на монотерапии диетой, у 3,0\% пациентов терапия в ФРСД была не указана.

Данные структуры терапии в динамике в период 2016-2020 гг. представлены в таблице 3. Отмечено уменьшение доли пациентов на ССП в монотерапии с 51,5 до 46,4\% с перераспределением в комбинированную терапию из 2 и более ССП, что является положительным моментом среди основных тенденций в назначении ССТ в РФ. Доля пациентов на инсулинотерапии при СД2 стабильна (19-20\%).

Структура распределения различных классов ССП и инъекционных неинсулиновых препаратов

Таблица 3. Структура терапии в динамике 2016-2020 гг., (\%, доля от пациентов с указанной медикаментозной терапией) по данным Федерального регистра пациентов с сахарным диабетом (84 региона)

\begin{tabular}{|c|c|c|c|c|c|c|}
\hline & Терапия & 2016 r. & 2017 r. & 2018 r. & 2019 r. & 2020 r. \\
\hline \multicolumn{2}{|c|}{ Количество пациентов, $\mathrm{n}$} & 3977544 & 4098881 & 4255508 & 4410233 & 4434876 \\
\hline \multicolumn{2}{|c|}{ Из них на медикаментозной терапии, n } & 3512809 & 3694949 & 3887985 & 4084827 & 4214708 \\
\hline \multicolumn{2}{|l|}{ ССП, \% } & 80,6 & 80,4 & 80,4 & 80,4 & 80,3 \\
\hline \multirow{3}{*}{ Из них } & Монотерапия ССП, \% & 51,5 & 50,2 & 49,2 & 47,9 & 46,4 \\
\hline & Комбинация 2 ССП, \% & 28,1 & 28,8 & 29,3 & 29,9 & 30,4 \\
\hline & Комбинация 3 и более ССП, \% & 1,0 & 1,4 & 1,9 & 2,6 & 3,4 \\
\hline \multicolumn{2}{|c|}{ Инсулинотерапия, \% } & 19,4 & 19,6 & 19,6 & 19,6 & 19,7 \\
\hline \multirow{2}{*}{ Из них } & Только инсулины, \% & 8,3 & 8,3 & 8,3 & 8,2 & 7,9 \\
\hline & Комбинация инсулины и ССП, \% & 11,1 & 11,3 & 11,2 & 11,4 & 11,8 \\
\hline
\end{tabular}




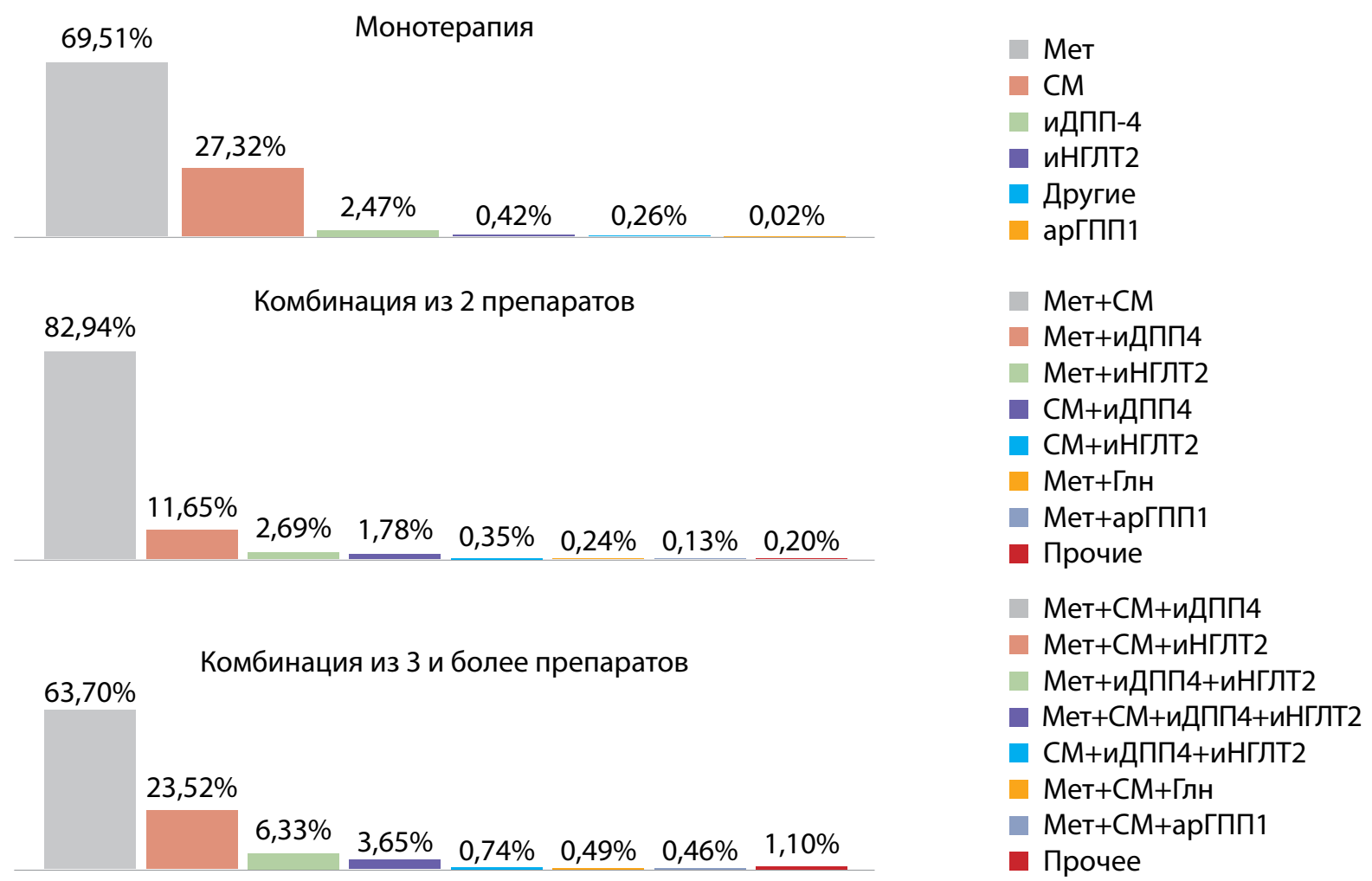

Рис. 22. Распределение неинсулиновых препаратов при сахарном диабете 2 типа при монотерапии, двойных и тройных комбинациях в Российской Федерации на 01.01.2021 г. Мет - метформин; СМ — препараты сульфонилмочевины; иДПП4 - ингибиторы дипептидилпептидазы-4; иНГлт2 ингибиторы натрий-глюкозного ко-транспортера-2; арГПП1 - агонисты рецепторов глюкагоноподобного пептида 1 типа.

в монотерапии, двойных и тройных комбинациях в 2020 г. представлена на рис. 22. В монотерапии наиболее часто назначаемыми препаратами были - метформин (Мет) (69,5\%), сульфонилмочевина (СМ) (27,3\%), ингибиторы дипептидилпептидазы-4 (иДПП-4) (2,5\%), другие классы препаратов составили суммарно менее 1\% монотерапии. Наиболее частыми двойными комбинациями были Мет+СМ 82,9\%, Мет+иДПП-4-11,7\%, Мет + ингибиторы натрий-глюкозного ко-транспортера 2 (иНГЛТ-2) - 2,7\%, СМ+иДПП-4 - 1,8\%, менее 1\% двойных комбинаций составляли: Мет + агонисты рецепторов глюкагоноподобного пептида 1 типа (арГПП-1) - 0,1\%. Доля новых классов препаратов возрастала в составе тройных комбинаций: Мет+СМ+иДПП-4 - 63,7\%, Мет+СМ+иНГЛТ-2 23,5\%, Мет+иДПП-4+иНГЛТ-2 - 6,3\%. Таким образом, наиболее часто назначаемыми препаратами как в монотерапии, так и в комбинациях остаются традиционные препараты Мет и СМ. Доля новых препаратов (иДПП-4, иНГЛТ-2) возрастает преимущественно в составе 3 комбинаций, в то время как назначение арГПП-1 остается без существенной динамики.

Нами также выполнен анализ динамики назначения различных классов препаратов при СД2, включая инсулины, в период 2016-2020 гг. (рис. 23). Выявлено, что

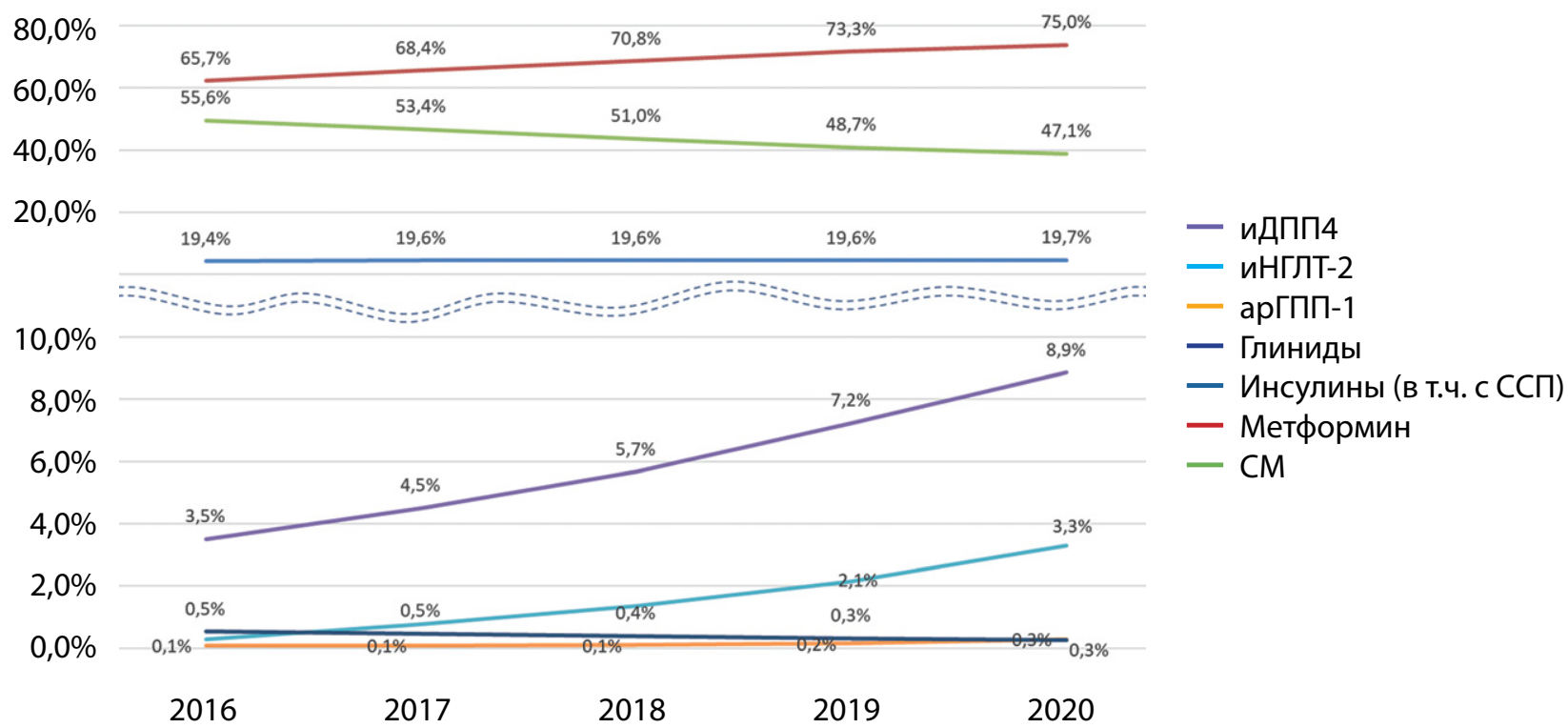

Рис. 23. Динамика назначения различных классов сахароснижающих препаратов и инсулинотерапии при сахарном диабете 2 типа по данным Федерального регистра пациентов с сахарным диабетом в Российской Федерации, 2016-2020 гг. 


\section{СД 1}

СД 2

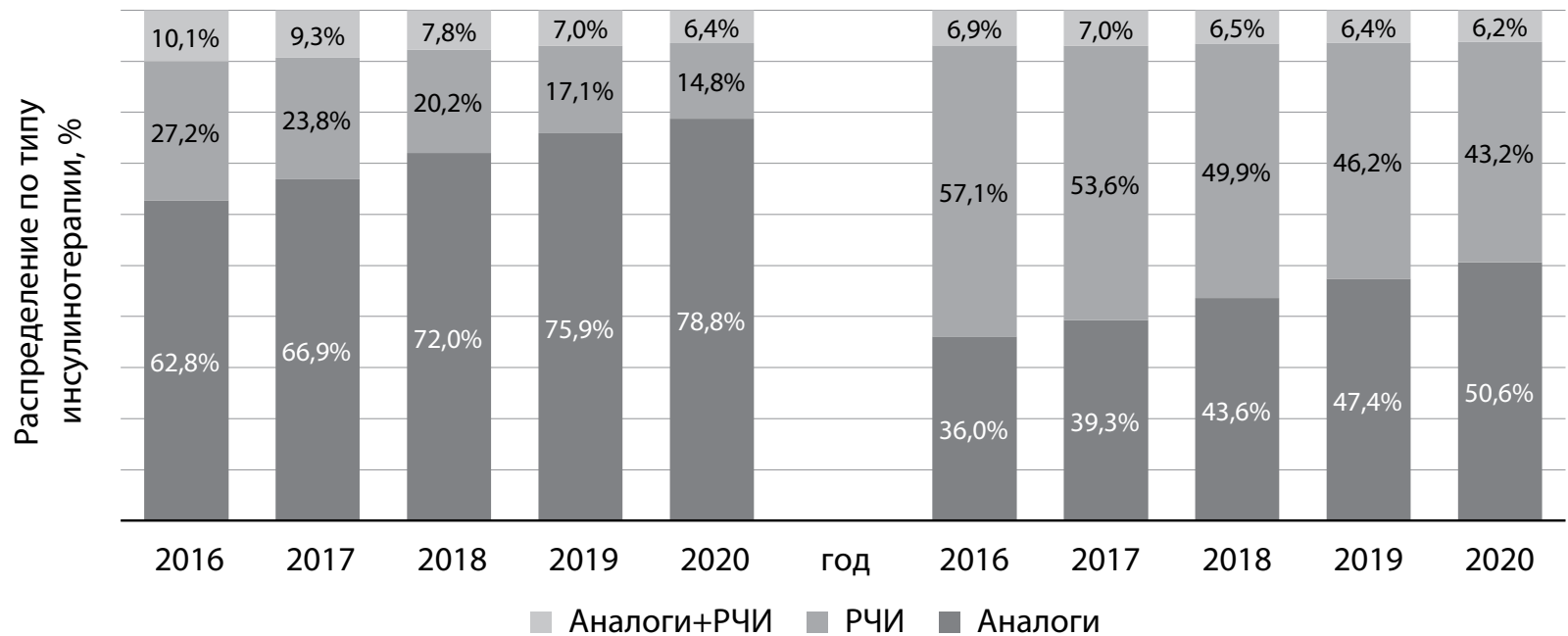

Рис. 24. Динамика структуры инсулинотерапии (аналоги инсулина человека, рекомбинантных человеческих инсулинов (РчИ), их комбинация) у пациентов с сахарным диабетом по данным Федерального регистра пациентов с сахарным диабетом, 2016-2020 гг.

в динамике за период 2016-2020 гг. уменьшилось использование препаратов СМ с 55,6 до 47,1\% (-8,5\%), назначение метформина возросло с 65,7 до 75,0\% (+9,3\%), количество пациентов с СД2 на инсулинотерапии в динамике достаточно стабильно 19,4-19,7\%. Среди новых классов ССП наиболее заметно увеличилась доля иДПП-4, более чем в 2 раза, с 3,5 до 8,9\% и иНГЛТ-2 - с 0,1\% до 3,3\%. Доля пациентов на терапии арГПП-1 осталась без существенной динамики - 0,1-0,3\%.

Выбор грамотной ССТ, направленной на достижение индивидуальных целей гликемического контроля и профилактику рисков развития диабетических осложнений, определяет долгосрочный прогноз пациента.

При этом важнейшим аспектом является ранняя интенсификация терапии на самых начальных этапах течения СД с целью первичной профилактики развития осложнений. При уровне $\mathrm{HbA}_{1 c}>1 \%$ индивидуальных целевых значений уже в дебюте заболевания или в кратчайшие сроки после его развития (не более 6 месяцев) рекомендуется назначение комбинированной терапии. Учитывая гетерогенность и многофакторность механизмов повышения гликемии при СД2, предпочтительно использование ССП с различными механизмами действия. В настоящее время, согласно современным клиническим рекомендациям, основанным на результатах масштабных клинических исследований, происходит изменение парадигмы подходов к ССТ: мы уходим от глюкозо-центрической модели терапии, учитывающей только сахароснижающую эффективность, ключевым приоритетом выбора становится применение препаратов с доказанными преимуществами снижения рисков развития сердечно-сосудистых и почечных исходов $[12,15]$.

К сожалению, на данном этапе, несмотря на положительную динамику уменьшения доли пациентов на монотерапии, согласно анализу ФРСД, становится очевиден факт недостаточной интенсификации ССТ в целом, в том числе с использованием инновационных препаратов, что требует изменения подходов к выбору терапии в условиях реальной клинической практики.

Аспекты безопасности ССТ, в том числе риски развития гипогликемий, имеют приоритетное значение при выборе препарата. Ранее по данным регистра нами было показано, что при уменьшении общего количества ком в последние годы отмечается перераспределение соотношения кетоацидотических и гипогликемических ком с увеличением доли гипогликемических состояний, особенно выраженное при СД2 [16]. Этот факт требует внимания со стороны практического здравоохранения и заставляет задуматься о том, что при выборе ССТ мы, безусловно, должны отдавать предпочтение тем препаратам, которые обладают меньшим риском развития гипогликемий.

На рис. 24 показана структура инсулинотерапии применение различных видов инсулинов в динамике 2016-2020 гг. у пациентов с СД1 и СД2: рекомбинантных человеческих инсулинов (РЧИ), аналогов инсулина или их сочетанное использование. Отмечено увеличение доли аналогов инсулина человека с 62,8 до 78,8\% при СД1 и с 36,0 до 50,6\% при СД2, уменьшение доли РЧИ с 27,2 до 14,8\% при СД1 и с 57,1 до 43,2\% при СД2.

При анализе данных регистра важнейшее значение имеет оценка эффективности внедрения новых диагностических и терапевтических методов, в том числе использования помповой инсулинотерапии. Мы проанализировали частоту использования аналогов инсулина и помп в группе детей и подростков (возраст до 18 лет) при СД1. Доля назначения аналогов инсулина в этой группе увеличилась за последние 5 лет с 91,4 до 97,3\% (рис. 25); отмечена положительная динамика применения помповой инсулинотерапии: с 2016 г. прирост составил 5\% (с 14 до 19\%), что в абсолютных значениях означает увеличение с 4549 до 8238 человек, таким образом, продолжается позитивная тенденция по увеличению охвата детей и подростов самыми современными видами инсулинотерапии [17].

\section{ЗАКЛЮЧЕНИЕ}

ФРСД является уникальной информационно-аналитической платформой для осуществления клинико-эпидемиологического мониторинга СД, анализа и развития службы диабетологической помощи в РФ на основе данных реальной клинической практики, ключевым инструментомв структуресистематизацииэпидемиологических 


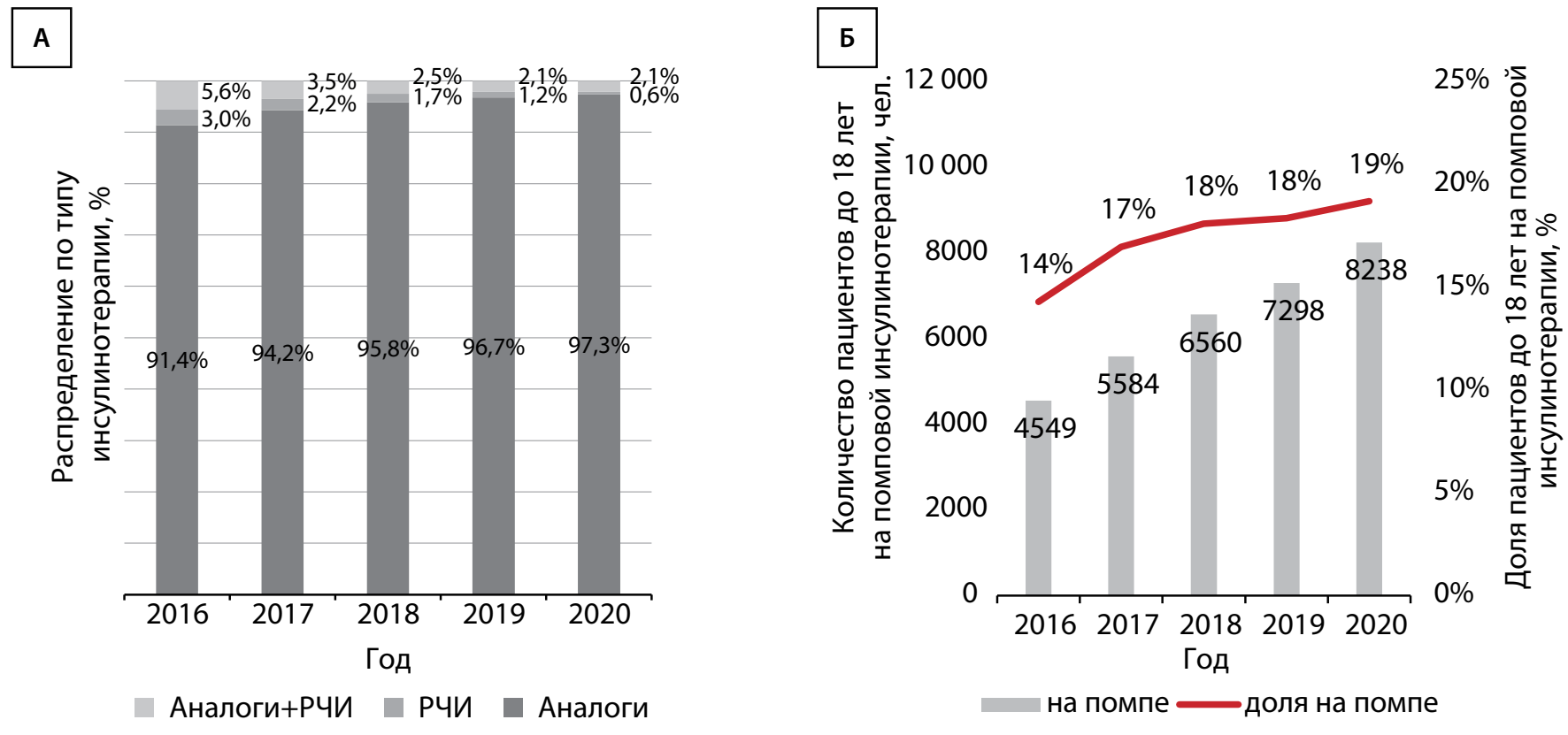

Рис. 25. Динамика структуры инсулинотерапии (аналоги, рекомбинантные человеческие инсулины (РчИ), их сочетание) (А) и данные помповой инсулинотерапии у детей и подростков с сахарным диабетом 1 типа (до 18 лет) (Б) по данным Федерального регистра пациентов с сахарным диабетом, 2016-2020 гг.

и клинических характеристик пациентов с СД на федеральном и региональном уровнях.

В статье представлены динамический анализ эпидемиологических показателей СД в РФ, распространенности осложнений, состояния углеводного обмена и динамика структуры ССТ - данных, необходимых для оценки качества оказания медицинской помощи и планирования развития диабетологической службы в РФ, в том числе с целью мониторинга регионов в рамках деятельности НМИЦ для решения задач, поставленных Национальным проектом «Здравоохранение».

Анализ ФРСД дает возможность оценивать параметры и динамику уровня $\mathrm{HbA}_{1 c^{\prime}}$ который, согласно Приказу №203н от 10 мая 2017 г. «Об утверждении критериев оценки качества медицинской помощи», регламентируется как обязательный показатель для включения в обследование пациентов с СД с целью оптимизации ССТ. В ключевые параметры документа входят также расчет индивидуального целевого уровня $\mathrm{HbA}_{1 с}$ и целевые значения гликемии. Усилия по обеспечению исследованием $\mathrm{HbA}_{1 с}$ 100\% пациентов с СД должны стать приоритетным направлением работы службы в каждом регионе. С 2020 г. показатель $\mathrm{HbA}_{1 с}$ внедрен во второй этап диспансеризации групп риска.

В последние два года в систему ФРСД были введены элементы автоматизированного контроля, обеспечивающего правильность установления типа СД и своевременной диагностики ряда осложнений. Создана система поддержки принятия решений и оценки качества оказания медицинской помощи для обеспечения рациональной, соответствующей клиническим рекомендациям терапии и тактики ведения этого социально значимого заболевания. Возможности онлайн-регистра по оценке терапии:

- пофамильные списки пациентов по виду терапии (ССП, арГПП1, инсулины, помповая терапия);

- списки пациентов по федеральной и региональной льготам;

- автоматический расчет индивидуальной потребности в упаковках препарата на квартал и на год (раздел автоматически заполняется в таблице при внесении дозы препарата);

- отчет о потребности в лекарственных препаратах по ТН и МНH;

- формирование «Протокола врачебной комиссии» назначаемой лекарственной терапии (подтверждение дозы и конкретного наименования препарата);

- формирование карты диспансерного учета;

- формирование пофамильных списков пациентов, имеющих показания для изменения терапии, резерв лекарственной заявки.

В условиях нового времени ФРСД представляет собой яркий пример информатизации на уровне первичного звена, обеспечивающего дистанционный контроль клинических данных пациентов с СД на федеральном и региональном уровнях. Расширение и совершенствование автоматизированной поддержки принятия клинических решений в перспективе должно обеспечить реализацию нового подхода к функциям ФРСД как системе контроля стратегических рисков заболевания.

\section{ДОПОЛНИТЕЛЬНАЯ ИНФОРМАЦИЯ}

Финансирование работы. Работа проведена в рамках выполнения Государственного задания Министерства здравоохранения Российской Федерации No AАAА-А19-119060690023-7.

Конфликт интересов. Авторы декларируют отсутствие явных и потенциальных конфликтов интересов, связанных с публикацией настоящей статьи.

Участие авторов. Шестакова М.В., Викулова О.К., Железнякова А.В., Исаков М.А. - анализ и интерпретация результатов исследования, написание текста статьи; Дедов И.И. - финальный анализ результатов и редактирование текста рукописи.

Благодарности. АО «Астон Консалтинг» за техническое сопровождение регистра СД в онлайн-формате.

Всем медицинским специалистам (врачам, медицинским сестрам, регистраторам данных), ведущим активную работу по заполнению базы данных регистра СД. 


\section{СПИСОК ЛИТЕРАТУРЫ | REFERENCES}

1. IDF Diabetes Atlas, 9th edition. Brussels: International Diabetes Federation; 2019; Available from: https://www.diabetesatlas.org/en/

2. Дедов И.И., Шестакова М.В., Викулова О.К., и др. Атлас регистра сахарного диабета Российской Федерации. Статус 2018 г. // Сахарный диабет. - 2019. - № 22(2S). - C. 4-61. [Dedov II, Shestakova MV, Vikulova OK, et al. Atlas of the diabetes register of the Russian Federation. Status 2018. Diabetes Mellitus. 2019;22(2S):4-61. (In Russ.)]. doi: https://doi.org/10.14341/DM12208

3. Дедов И.И., Шестакова М.В., Викулова О.К. Государственный регистр сахарного диабета в Российской Федерации: статус 2014 г. и перспективы развития // Сахарный диабет. - 2015. T. 18. — №3. - C. 5-22. [Dedov II, Shestakova MV, Vikulova OK. National register of diabetes mellitus in Russian Federation: status on 2014. Diabetes mellitus. 2015;18(3):5-23. (In Russ.)]. doi: https://doi.org/10.14341/DM201535-22

4. Шестакова М.В., Викулова О.К., Исаков М.А., Дедов И.И. Сахарный диабет и COVID-19: анализ клинических исходов по данным регистра сахарного диабета Российской Федерации // Проблемы эндокринологии. — 2020. - Т. 66. — № 1. — С. 35-46. [Shestakova MV, Vikulova OK, Isakov MA, Dedov II. Diabetes and COVID-19: analysis of the clinical outcomes according to the data of the Russian Diabetes Registry. Problems of Endocrinology. 2020;66(1):35-46. (In Russ.)]. doi: https://doi.org/10.14341/probl12458

5. Федеральная служба государственной статистики. Доступно по: gks.ru. [Russian Federal State Statistics Service. Available from: www.gks.ru. (In Russ.)]

6. Дедов И.И., Шестакова М.В., Викулова О.К. Эпидемиология сахарного диабета в Российской Федерации: клиникостатистический анализ по данным Федерального регистра сахарного диабета // Сахарный диабет. - 2017. - Т. 20. №1. - C. 13-41. [Dedov II, Shestakova MV, Vikulova OK. Epidemiology of diabetes mellitus in Russian Federation: clinical and statistical report according to the federal diabetes registry. Diabetes mellitus. 2017;20(1):13-41. (In Russ.)]. doi: https://doi.org/10.14341/DM8664

7. Дедов И.И., Шестакова М.В., Викулова О.К., и др. Сахарный диабет в Российской Федерации: распространенность, заболеваемость, смертность, параметры углеводного обмена и структура сахароснижающей терапии по данным Федерального регистра сахарного диабета, статус 2017 г. // Сахарный диабет. - 2018. T. 21. — №3. — C. 144-159. [Dedov II, Shestakova MV, Vikulova OK, et.al. Diabetes mellitus in Russian Federation: prevalence, morbidity, mortality, parameters of glycaemic control and structure of hypoglycaemic therapy according to the Federal Diabetes Register, status 2017. Diabetes Mellitus. 2018;21(3):144-159. (In Russ.)]. doi: https://doi.org/10.14341/DM9686

8. Письмо Минздравсоцразвития РФ от 26.04.2011 №14-9/10/24150 Доступно по: http://base.garant.ru/4192897/ [Pis'mo Minzdravsotsrazvitiya RF ot 26.04.2011 №14-9/10/2-4150 Available from: http://base.garant.ru/4192897/ (In Russ.)].

9. Данные Росстата, Демографический ежегодник России 2019. Доступно по: https://gks.ru/folder/210/document/13207. [Dannye Rosstata, Demograficheskil ezhegodnik Rossii. 2019. Available from: https://gks.ru/folder/210/document/13207 (In Russ.)].

10. Железнякова А.В., Викулова О.К., Серков А.А., и др. Динамический мониторинг сердечно-сосудистых заболеваний у пациентов с сахарным диабетом по данным обследования в мобильном медицинском центре (Диамодуль) в регионах России // Consilium Medicum. - 2020. - T. 22. - №10. - C. 39-44. [Zheleznyakova AV, Vikulova OK, Serkov AA, et al. Dynamic monitoring of cardiovascular diseases in patients with diabetes mellitus according to mobile medical center (Diamodule) in the regions of Russia. Consilium Medicum. 2020;22 (10):39-44. (In Russ.)]. doi: https://doi.org/10.26442/20751753.2020.10.200323

11. Шестакова М.В., Викулова О.К., Железнякова А.В., и др. Эпидемиология сахарного диабета в Российской Федерации: что изменилось за последнее десятилетие? // Терапевтический архив. — 2019. - Т. 91. — №10. — C. 4-13. [Shestakova MV, Vikulova OK, Zheleznyakova AV, et al. Diabetes epidemiologyin Russia: what has changed over the decade? Therapeutic Archive. 2019;91(10):4-13. (In Russ.)]. doi: https://doi.org/10.26442/00403660.2019.10.000364

12. Дедов И.И., Шестакова М.В., Майоров А.Ю., и др. Алгоритмы специализированной медицинской помощи больным сахарным диабетом: Клинические рекомендации (Вып. 9) // Сахарный дuaбem. - 2019. - T. 22. — №S1. — C. 1-144. [Dedov II, Shestakova MV, Mayorov AY, et al. Standards of specialized diabetes care. 9th edition. Diabetes Mellit. 2019;22(1S1):1-121. (In Russ.)]. doi: https://doi.org/10.14341/DM221S1

13. Викулова О.К., Железнякова А.В., Исаков М.А., и др. Динамический анализ состояния углеводного обмена в субъектах Российской Федерации по данным мобильного медицинского центра (Диамодуль) и регистра сахарного диабета Российской Федерации // Сахарный диабет. — 2020. — Т. 23. — №2. C. 104-112. [Vikulova OK, Zheleznyakova AV, Isakov MA, et al. Dynamic analysis of glycaemic control parameters in the regions of Russia according to the data of the mobile medical centre (Diamodul) and Federal Diabetes Register. Diabetes Mellitus. 2020;23(2):104-112. (In Russ.)]. doi: https: doi.org/10.14341/DM12327

14. Дедов И.И., Шестакова М.В., Майоров А.Ю., и др. Сахарный диабет 1 типа у взрослых. Клинические рекомендации // Сахарный диабет. - 2020. - Т. 23. — №1S. - C. 42-114. [Dedov II, Shestakova MV, Mayorov AY, et al. Diabetes mellitus type 1 in adults. Diabetes mellitus. 2020;23(1S):42-114. (In Russ.)]. doi: https://doi.org/10.14341/DM12505

15. Дедов И.И., Шестакова М.В., Майоров А.Ю., и др. Сахарный диабет 2 типа у взрослых. Клинические рекомендации // Сахарный диабет. - 2020. - Т. 23. - №2S. - C. 4-102. [Dedov II, Shestakova MV, Mayorov AY, et al. Diabetes mellitus type 2 in adults. Diabetes mellitus. 2020;23(2S):4-102. (In Russ.)] doi: https://doi.org/10.14341/DM12507

16. Майоров А.Ю., Викулова О.К., Железнякова А.В., и др. Эпидемиология острых осложнений (комы) по данным Федерального регистра больных сахарным диабетом Российской Федерации (2013-2016 гг.) // Сахарный диaбem. - 2018. - T. 21. — №6. - C. 444-454. [Mayorov AY, Vikulova OK, Zheleznyakova AV, et al. Epidemiology of acute diabetes complications (coma) according to the Federal Diabetes register of the Russian Federation (2013-2016). Diabetes Mellitus. 2018;21(6):444-454. (In Russ.)]. doi: https://doi.org/10.14341/DM10028

17. Дедов И.И., Шестакова М.В., Петеркова В.А., и др. Сахарный диабет у детей и подростков по данным Федерального регистра Российской Федерации: динамика основных эпидемиологических характеристик за 2013-2016 гг. // Сахарный duaбem. - 2017. - T. 20. — №6. - C. 392-402. [Dedov II, Shestakova MV, Peterkova VA et al. Diabetes mellitus in children and adolescents according to the Federal diabetes registry in the Russian Federation: dynamics of major epidemiological characteristics for 2013-2016. Diabetes mellitus. 2017;20(6):392-402. (In Russ.)] doi: https://doi.org/10.14341/DM9460

\section{ИНФОРМАЦИЯ ОБ АВТОРАХ [AUTHORS INFO]}

*Викулова Ольга Константиновна, К.М.н., доцент [Olga K. Vikulova, MD, PhD, associate professor]; адрес: Россия, 117036, Москва, ул. Дм.Ульянова, д. 11 [address: 11 Dm.Ulyanova street, 117036 Moscow, Russia]; eLibrary SPIN: 9790-2665; ORCID: https://orcid.org/0000-0003-0571-8882; e-mail: gos.registr@endocrincentr.ru

Дедов Иван Иванович, д.м.н., профессор, академик PAH [Ivan I. Dedov, MD, PhD, Professor]; ORCID: https://orcid.org/0000-0002-8175-7886; eLibrary SPIN: 5873-2280; e-mail: dedov@endocrincentr.ru Шестакова Марина Владимировна, д.м.н., профессор, академик РАH [Marina V. Shestakova, MD, PhD, Professor]; ORCID: https://orcid.org/0000-0003-3893-9972; eLibrary SPIN: 7584-7015; e-mail: nephro@endocrincentr.ru 
Железнякова Анна Викторовна, к.M.H. [Anna V. Zheleznyakova, MD, PhD]; ORCID: https://orcid.org/0000-0002-9524-0124; eLibrary SPIN: 8102-1779; e-mail: azhelez@gmail.com

Исаков Михаил Андреевич, к.б.н. [Mikhail A. Isakov, PhD in Biology]; ORCID: https://orcid.org/0000-0001-9760-1117; eLibrary SPIN: 5870-8933, e-mail: m.isakov@aston-health.com

\section{ЦИТИРОВАТЬ:}

Дедов И.И., Шестакова М.В., Викулова О.К., Железнякова А.В., Исаков М.А. Эпидемиологические характеристики сахарного диабета в Российской Федерации: клинико-статистический анализ по данным Федерального регистра сахарного диабета на 01.01.2021 // Сахарный диабет. — 2021. — Т. 24. — №3. — C. 204-221. doi: https://doi.org/10.14341/DM12759

\section{TO CITE THIS ARTICLE:}

Dedov II, Shestakova MV, Vikulova OK, Zheleznyakova AV, Isakov MA. Epidemiological characteristics of diabetes mellitus in the Russian Federation: clinical and statistical analysis according to the Federal diabetes register data of 01.01.2021. Diabetes Mellitus. 2021;24(3):204-221. doi: https://doi.org/10.14341/DM12759 